The Dyadic Health Influence Model

Personality and Social Psychology Review (In Press)

Chloe O. Huelsnitz ${ }^{1}$, Rachael E. Jones ${ }^{1}$, Jeffry A. Simpson ${ }^{1}$, Keven Joyal-Desmarais ${ }^{2-3}$, Erin C. Standen ${ }^{1}$, Lisa A. Auster-Gussman ${ }^{4}$, \& Alexander J. Rothman ${ }^{1}$

${ }^{1}$ University of Minnesota, ${ }^{2}$ Concordia University, ${ }^{3}$ Montreal Behavioral Medicine Centre, ${ }^{4}$ Northwesten University Feinberg School of Medicine

Author Note: The first two authors contributed equally to the preparation of this manuscript. All authors contributed to the theoretical development of the Dyadic Health Influence Model. $\mathrm{COH}$ and REJ wrote the initial version of the manuscript with support from JAS and AJR; KJD, ECS, and LAAG provided substantive feedback on the manuscript. All authors read and approved this manuscript. We would also like to thank Drs. Paula Pietromonaco, Urte Scholz, and Allison Farrell for providing feedback on an earlier version of this manuscript prior to manuscript submission. 


\begin{abstract}
Relationship partners affect one another's health outcomes through their health behaviors, yet how this occurs is not well understood. To fill this gap, we present the Dyadic Health Influence Model (DHIM). The DHIM identifies three routes through which a person (the agent) can impact the health beliefs and behavior of their partner (the target). An agent may: (1) model health behaviors and shape the shared environment, (2) enact behaviors that promote their relationship, and/or (3) employ strategies to intentionally influence the target's health behavior. A central premise of the DHIM is that agents act based on their beliefs about their partner's health and their relationship. In turn, their actions not only have consequences for targets' health behavior, but also for their relationship. We review theoretical and empirical research that provides initial support for the routes and offer testable predictions at the intersection of health behavior change research and relationship science.
\end{abstract}

Keywords: Close relationships, health behavior change, social control, social influence, modeling 


\section{The Dyadic Health Influence Model}

Over the last several decades, researchers have documented the critical interplay between close relationships and health. Close relationship partners - and the quality of relationships with partners - impact mortality and morbidity and their underlying determinants (Holt-Lunstad, 2018; Brown et al., 2018; Leigh-Hunt et al., 2017; Robles et al., 2014; Valtorta et al., 2016). This work has primarily examined the effects of relationship functioning on biological stress-related pathways and/or psychosocial pathways that impact health, whereas the interplay between relationship functioning and health behaviors has been relatively understudied (Pietromonaco \& Collins, 2017). Given the effect health behaviors have on overall short-term and long-term health outcomes (Bauer et al., 2014; McGinnis et al., 2002), understanding the ways in which relationship partners shape each other's health beliefs and behavior is crucial.

Although investigators recognize that partners matter, effectively leveraging their impact on behavior change has been surprisingly difficult (e.g., Carr et al., 2019; Faseru et al., 2018; Gorin et al., 2020). A key challenge for these efforts has been the absence of a theoretical model that maps the different ways in which close relationship partners directly and indirectly shape each other's health behavior. We propose three routes by which they may do so: partners can serve as models of healthy behavior; they can cultivate a supportive interpersonal environment within which their partner can manage their health behavior; and they can employ strategies designed to influence their partner's behavior. This paper presents a new model - the Dyadic Health Influence Model (DHIM) - that describes each of these routes and, in doing so, maps how the interplay between key interpersonal and intrapersonal processes jointly affect health behavior change in close relationships. By recognizing the different ways in which partners can affect one another's health behavior, the DHIM provides investigators with a structure to organize the 
existing literature, revealing what is currently known about these processes and what remains unknown or untested, and a framework for specifying how to capitalize on the potential impact of close relationship partners. Importantly, the DHIM also emphasizes the need to examine the impact of these three routes on relational outcomes in addition to health outcomes. We argue that the effects of partner behaviors on both health and relational outcomes, together, will determine the success of efforts to promote the initiation and maintenance of health behavior change.

\section{The Need for an Integrated Model of Relationships and Health Behavior}

There are myriad ways in which relationship partners might affect and be affected by each other's health and health behaviors (Pietromonaco \& Collins, 2017; Slatcher \& Selcuk, 2017; Umberson et al., 2010). For instance, research has shown that, within a relationship, changes in the health behavior of one partner can elicit similar changes in the behavior of the other partner (Jackson et al., 2015), and interventions to change health behaviors in one person can have "ripple" effects on the health behaviors of their close relationship partners (e.g., Golan et al., 2010; Gorin et al., 2008; White et al., 1991).

There is also mounting evidence that certain characteristics of close partners and relationships (e.g., interdependence: the degree to which each partner's outcomes are dependent on the other's) creates a social context that is marked by support and connectedness, which, in turn, promote key psychosocial (e.g., emotion, coping; Kiecolt-Glaser et al., 2002; Pietromonaco et al., 2013; Slatcher \& Selcuk, 2017) and biological processes (e.g., immune function; Gouin et al., 2009; Robles \& Kane, 2014, Uchino, 2006). This environment affects not only distal health outcomes such as morbidity and mortality (e.g., Holt-Lunstad et al., 2010), but also more proximal outcomes such as treatment adherence (e.g., DiMatteo, 2004), stress reduction (e.g., Hostinar, 2015), and chronic illness management (e.g., Martire \& Helgeson, 2017). 
Investigators have also documented how close others deliberately try to shape each other's health beliefs and health behaviors, referred to here as health-related influence strategies, but also known as social control strategies (Hughes \& Gove, 1981; Lewis \& Rook, 1999; Umberson, 1987; see Craddock et al., 2015 for a meta-analysis of the effects of social control on health behaviors and wellbeing). Efforts to map how relationship partners try to modify each other's behavior have led investigators to recognize the interpersonal context in which people's health behavior typically unfolds (e.g., Lewis et al., 2006; Pietromonaco \& Collins, 2017). However, there is a need for investigators to move from describing which health-related influence strategies are used toward formulating and testing hypotheses regarding when and why these strategies affect behavior and well-being (Craddock et al., 2015).

Although investigators recognize the different routes through which relationship partners can shape each other's behavior (e.g., Berli et al., 2018a; Fitzsimons et al., 2015; Hohl et al., 2016; Lewis et al., 2006; Loving \& Slatcher, 2013; Lüscher et al., 2019; Martire et al., 2010; Novak, 2019; Pietromonaco et al., 2013; Slatcher \& Selcuk, 2017; Skoyen et al., 2013; Zee et al., 2020), prior work has not highlighted or drawn out the manner in which these routes complement, compensate, or intersect with each other. This state of affairs is not surprising given the limited theoretical guidance investigators have had regarding how the interpersonal processes that unfold within a relationship map onto the intrapersonal processes that guide how people manage their health behavior.

Research and theory in relationship science, for example, has provided a rich description of the verbal and non-verbal behaviors that people use to shape the thoughts and feelings of others along with the conditions under which these strategies tend to be used and are most effective (e.g., Jayamaha et al., 2016; Oriña et al., 2008; Overall et al., 2009; Overall et al., 2013; 
see Simpson et al., 2015, ). Although relationship scientists have documented how these interpersonal processes affect relational outcomes, these descriptions say little about implications for health behaviors. For instance, how and when can these strategies be deployed to facilitate changes in partners' health beliefs and behaviors? To what extent are strategies that elicit favorable relational outcomes also likely to elicit favorable health outcomes?

Research and theory on health behavior change, on the other hand, has focused primarily on delineating intrapersonal processes that impact health behavior (e.g., Rothman \& Salovey, 2007; Conner \& Norman, 2017). Through these efforts, we understand the cognitions, emotions, and skills that guide individuals' health behavior, which, in turn, provides a working list of psychological processes that relationship partners might try to engage. Some people, for instance, may benefit from influence strategies that help them recognize the personal relevance of a health threat, whereas others might benefit from those that help them develop the skills needed to engage in a new pattern of behavior. Yet, models of health behavior offer no guidance regarding how interpersonal process might be used to engage these targeted constructs.

Research on health behavior change in interpersonal contex ts has developed a taxonomy of health-related influence strategies and underlying tactics used in romantic relationships (Butterfield \& Lewis, 2002; Lewis et al., 2004; Lewis \& Butterfield, 2007) and has worked to map the effect of these strategies on people's emotions regarding their partner's attempts to change their health behavior as well as the effect of these strategies on people's health behaviors (Lewis \& Rook, 1999; Newsom et al., 2018; Okun et al., 2007). Yet, given their prevailing focus on changes in health and health behavior within individuals, these models are less attentive to how the pursuit of such changes might affect important relational outcomes. For instance, healthrelated influence strategies that elicit favorable changes in health behavior may or may not have 
a favorable effect on key relational outcomes such as relationship satisfaction. Health-related influence strategies that produce favorable changes to an individual's health behavior might be considered effective, but if they have adverse effects on their relationship, partners may be reluctant to use them.

By developing theoretical models that engage both relational and health behavior outcomes, investigators will be in a better position to generate and test predictions regarding how characteristics of both individuals (e.g., their perceptions of their own as well as their partner's health behavior and beliefs) and relationships (e.g., their degree of interdependence and reciprocity) shape how close others regulate each other's health behavior.

\section{Orientation to the Dyadic Health Influence Model (DHIM)}

The Dyadic Health Influence Model (DHIM; Figure 1) describes three primary routes through which one partner in a relationship (i.e., the agent $^{\mathbf{1}}$ of health behavior change) can affect the health beliefs and/or behavior of the other partner (i.e., the target of health behavior change). These routes capture processes associated with (1) the agent's own health behavior (the health behavior transmission route), (2) the relationship between the agent and target (the relational behavior route), and (3) health-related influence strategies enacted by the agent (the influence strategies route).

The health behavior transmission route in the DHIM (Route A, indicated by the boxes on the left-hand side of the model in Figure 1) focuses on the agent's own health beliefs and behavior. For example, it depicts how the agent's beliefs about their own health can affect their own health behavior, which in turn may directly or indirectly affect the target's health beliefs and behavior. Next, the relational behavior route in the DHIM (Route B, indicated by the boxes on

\footnotetext{
${ }^{1}$ Bolded terms and phrases are those used in the DHIM. Italics are used for emphasis.
} 
the right side of the model) identifies ways in which the agent's relational beliefs and behavior can facilitate the link between the target's health beliefs and health behaviors by reducing the target's stress or by increasing their self-esteem or self-compassion. The agent's relational beliefs may also indirectly affect the target's health behavior through the selection and use of health-related influence strategies (hereafter referred to as influence strategies). Finally, the influence strategies route in the DHIM (Route $\mathrm{C}$, indicated by the boxes in the center of the model) focuses on the influence strategies the agent intentionally uses to attempt to modify the target's health beliefs and behavior. Finally, the feedback paths in the DHIM illustrate that these efforts unfold over time and, in doing so, create a relational and health history between the agent and the target - a feature that has not been sufficiently integrated into existing theoretical models of interpersonal processes (Eastwick et al., 2019), including those addressing health behavior (Reed et al., 2013; Scholz, 2019).

Figure 1. The Dyadic Health Influence Model. The solid black lines refer to the paths in the three central routes (Section I). The dashed, black lines represent the ways in which the target's relational beliefs moderate other routes (Section II). The solid gray lines on the outside of the figure illustrate the feedback paths (Section III). The light gray, dotted lines represent paths that exist but are not central to the core tenets of the DHIM and, therefore, are minimally discussed. The square boxes represent the agent's beliefs and behaviors. The ovals represent the target's beliefs and behaviors. 


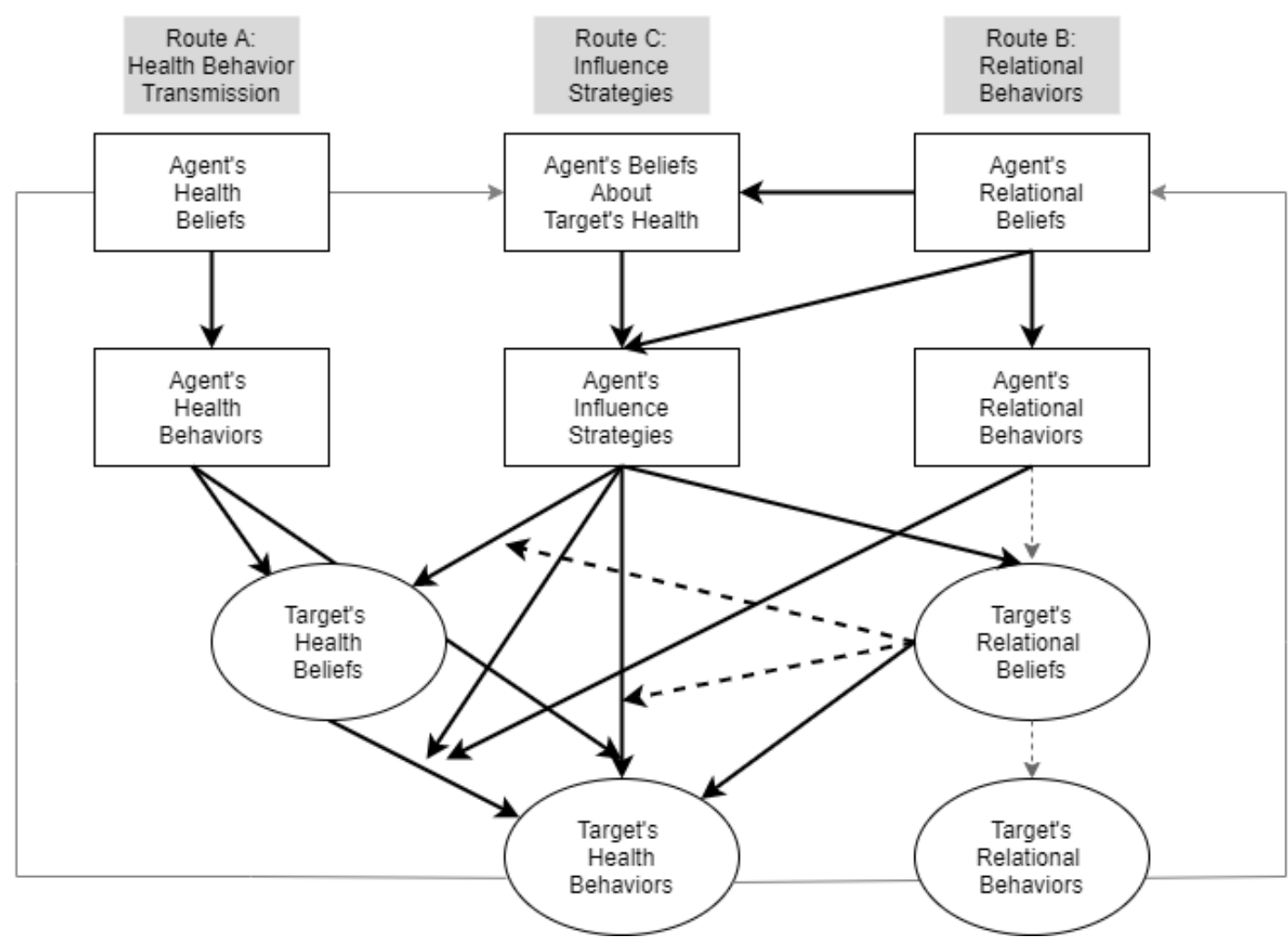

\section{Parameters and Scope of the DHIM}

Five parameters guided the development of the model. First, the DHIM is a dyadic model. Each partner in a relationship can be simultaneously the target (whose health behavior change is the focus of the model) and the agent (whose actions generate the target's health behavior change). However, unlike most dyadic models (e.g., which have a similar structure to the Actor-Partner Interdependence Model; Kenny et al., 2006), the DHIM is a theoretical process model in which only one partner is an agent in any given situation while the other partner is a target. We chose this layout to demonstrate more clearly how the precursors and consequences of each person's behavior affect the other person's behavior in ways that reverberate back into the relationship over time.

Second, the agent's health behaviors, relational behaviors, and influence strategies are conceptualized from the perspective of the agent (rather than the target) to disentangle the effects 
of the agent's intention and the target's perceptions. Within the DHIM, influence strategies are engaged in intentionally by the agent to change the target's behavior. However, their own health behaviors (e.g., their own diet), along with their relational behaviors towards the target (e.g., supporting the target) are not engaged in with the intention of changing the target's behavior.

Third, although the DHIM is designed to be applicable across different types of relationships, we focus on implications for adult individuals involved in romantic relationships. We begin here because adult romantic relationships are characterized by not only high levels of motivation for interdependence, but also opportunities for interdependence through cohabitation, shared routines, and overlapping social networks (Agnew et al., 1998; Lewis et al., 2006; Kelly \& Thibaut, 1978). Additionally, much of prior theoretical and empirical work has focused on influence and health in romantic relationships (e.g., Berli et al., 2018a; Berli et al.; 2018b; Butterfield \& Lewis, 2002; Craddock et al., 2015; Hohl et al., 2018; Lewis \& Butterfield, 2007; Lüscher et al., 2017; 2019; Martire et al., 2010; Robles et al., 2014), which affords a large body of empirical evidence to inform theoretical development.

Fourth, the DHIM assumes the agent has good intentions; that they want the best health outcomes for the target. The DHIM, therefore, does not address relational behaviors or influence strategies that are enacted with mal-intent, although it recognizes that behaviors engaged in with positive intentions may sometimes result in adverse target reactions or behaviors. Relatedly, the DHIM focuses on behavior change that promotes better health. Although there are times when agents might want the target to engage in patterns of unhealthy behavior (e.g., substance use; Kehayes et al., 2017; Mushquash et al., 2013), these instances are not the focus of the model. Fifth, the DHIM is predicated on the assumption that research delineating the operation of any one of the three routes - health behavior transmission, relational behavior, influence 
strategies - must be mindful of the existence of the other routes. For example, the relational behavior route creates a context within which to understand the use and effectiveness of health behavior transmission (e.g., modeling) or specific influence strategies (e.g., directly limiting a partner's behavioral alternatives). Thus, agents who have more supportive or satisfactory relationships with targets may be able to rely on behavioral transmission (modeling) rather than overt influence strategies to induce changes in a targets' health behavior. And targets in better relationships might be better able to respond favorably to the strategies that their partners (agents) use to modify their behavior. Influence processes and effectiveness, in other words, cannot be fully understood without considering relationship factors.

Taken together, the DHIM provides a theoretical framework for conceptualizing the key routes through which relationship partners can affect one another's health-relevant behavior and outcomes. It also provides a framework within which existing empirical findings on how partners affect each other's health behavior can be placed and organized; allowing critical gaps in the current literature to be more readily identified and, eventually, addressed. The DHIM, therefore, is a catalyst for generating and testing hypotheses involving core constructs of the model (e.g., health beliefs, relational beliefs), allowing researchers to apply existing interpersonal and intrapersonal theories to formulate specific predictions with respect to specific health outcomes.

Given the scope of the model, we introduce each aspect of it incrementally in four sections of the paper. In Section I, we discuss what is and is not known regarding each of the three primary routes. In Section II, we describe how the target's beliefs about the agent and their relationship may determine whether and how agents are able to change the target's health behavior. In Section III, we describe how the DHIM may operate over time and, in partic ular, the iterative processes that link the agent's behavior and the target's response to the agent's 
behavior. Finally, in Section IV, we discuss contextual considerations, such as how features of the health behavior and features of the environment may affect different routes in the DHIM.

Figure 2. Primary routes in the DHIM. The solid black lines reflect the paths in the three central routes (Section I). The light grey, dotted lines represent pathways that exist but are not central to the core tenets of the DHIM and, therefore, are minimally discussed. The square boxes represent the agent's beliefs and behaviors. The ovals represent the target's beliefs and behaviors. The paths are labeled and correspond to their description in the text.

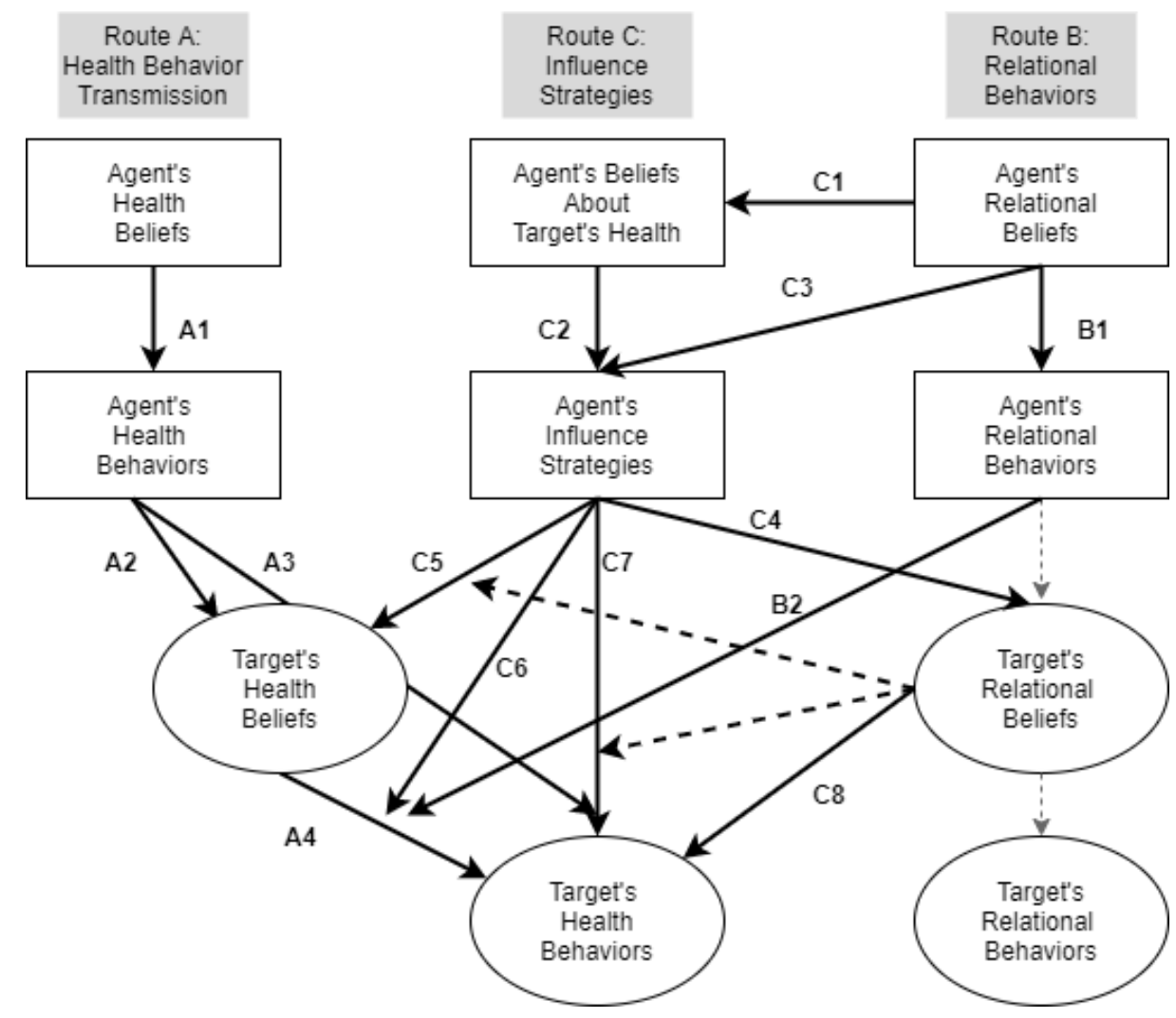

\section{Section I: Primary Routes from Agent's Beliefs and Behavior to Target's Beliefs and Behavior}

The primary routes posited by the DHIM include (A) the health behavior transmission route, (B) the relational behaviors route, and (C) the influence strategies route (see Figure 2 for 
path labels within each route). Each construct is described within its respective route; and for each of the arrows linking constructs (e.g., Agent's Beliefs About the Target's Health $\rightarrow$ Influence Strategies), we review the existing evidence for the connection between the constructs, identify gaps, and offer "Promising Research Directions," which illustrate predictions derived from the paths that will help advance research at the intersection of relationships and health.

\section{Route A: Health Behavior Transmission (How Agent's Health Beliefs Affect Agent's Health Behavior and Elicit Change in Target's Health Beliefs and/or Health Behavior)}

The first route in the DHIM (see Route A on the left side of Figure 2) illustrates the simplest way that an agent can affect the target's health behavior: through their own health behavior. In this route, we begin with the intrapersonal factors that have been central to many social cognitive models of health behavior (Rothman \& Salovey, 2007; Conner \& Norman, 2017), namely that an individual's health beliefs are a key determinant of their own health behavior. Health beliefs include constructs such as risk appraisals, attitudes toward the health behavior, norms for the behavior, and behavioral intentions; as well as perceptions of the self in relation to health, such as feeling capable of changing one's health behavior and achieving better health. This is not an exhaustive list of health beliefs that could be applied in the DHIM; rather, it reflects frequently studied beliefs that are supported by experimental evidence showing that changes in these classes of beliefs lead to changes in health behavior (e.g., Sheeran et al., 2016). Within the DHIM, these beliefs are the key proximal determinants of the agent's (A1) and target's (A4) health behavior and, in many cases, are the beliefs held by the target that may shift in response to the agent's behavior.

Agent's Health Behavior $\rightarrow$ Target's Health Beliefs (A2) 
In the health behavior transmission route (Route A), the agent is engaging in a health behavior in response to their own health beliefs. The agent's health behavior may then unintentionally lead to changes in the target's health beliefs. This shift in beliefs could reflect observational learning or imitation on the part of the target in response to what the agent typically does or responses by the target to changes to the shared environment the agent has made while in pursuit of their own health goals. Despite the intuitiveness of this prediction, little research in the context of romantic relationships has directly examined whether one partner's health behavior facilitates changes in the other's health beliefs. There is some evidence of concordance in partners' health beliefs, such as worry about risk of genetic conditions in one's family (Turbitt et al., 2018) and information avoidance (Huelsnitz et al., 2021). Although it is possible that targets' observations of agents' health behavior and/or changes the agent makes to their shared environment could explain concordance in these health beliefs, reasons for concordance in beliefs were not directly measured in these studies. Thus, it is important to assess whether agents' engagement in health behavior and/or the changes agents make to the shared environment cause changes in targets' health beliefs, which can then cause changes in targets' health behavior (A3).

\section{Agent's Health Behavior $\rightarrow$ Target's Health Behavior (A3)}

The agent's health behavior may also change the target's behavior directly, bypassing the target's health beliefs, via changes made to the shared environment and through modeling. Because the target and agent are relationship partners, the agent's environments and habits may affect what is available to the target (e.g., Theiss et al., 2016). If, for example, the agent and target share a living environment, and the agent buys whole fruit instead of potato chips for 
snacks, the target may end up eating more fruit simply because it is available, regardless of their beliefs about doing so.

A considerable body of research has documented concordance between romantic partners' health behaviors across behavioral domains (e.g., physical activity, smoking, alcohol consumption, diet [Birditt et al., 2018; Christakis \& Fowler, 2008; Myers Virtue et al., 2015; Pachucki et al., 2011]). However, most studies rely on cross-sectional data, which do not allow investigators to rule out the possibility that concordance is due to similarities between the partners and between their environments that predate their relationship.

The strongest evidence for a causal link between agents' and targets' health behavior comes from longitudinal studies and health behavior change interventions. Some studies have shown that, within a relationship, one partner's health behavior or health behavior change can elicit similar changes in the behavior of the other partner (Homish \& Leonard, 2008; Jackson et al., 2015; but see Brazeau \& Lewis, 2020), and that health interventions that target individuals can have "ripple" effects on the health and health behaviors of their relationship partners (e.g., Golan et al., 2010; Gorin et al., 2008; Schierberl Scherr et al., 2013; White et al., 1991).

\section{Promising Research Directions for Route A}

Behavioral concordance among romantic partners is well-established, but there is a need to specify how changes in one partner's health behaviors affect changes in the other partner's health behaviors. One potential explanation is that shifts in the health behavior of one partner affect the other partner's perception of how normative it is engage in that behavior (e.g., Chung \& Rimal, 2016; Reid et al., 2010), which then affects their likelihood of engaging in that behavior. For example, running may seem more normative to the target (a social norm) if an important part of their social circle (the agent) joins a running club. To date, research has not 
examined how changes in agents' health behavior affect targets' social norms regarding that behavior.

Another potential mechanism is self-efficacy, which has been shown to be responsive to behavioral modeling (often referred to as "vicarious experience;" Bandura, 1977) (e.g., Jiang et al., 2019; Rieder et al., 2021; Selzler et al., 2020); but see Warner et al., 2018). A next step for researchers is to examine whether targets who view their romantic partners succeed - or struggle - with engaging in a health behavior report changes in their own perceptions of self-efficacy. For instance, do people who see their partners struggle to lose weight feel less efficacious at losing weight, whereas those who observe their partner successfully modify their diet or physical activity as part of a weight-loss intervention report increased perceptions of efficacy?

This predicted pattern of effects is analogous to the observation that the behavioral effects of interventions can "ripple" from a treated individual to their untreated partner (e.g., Gorin et al., 2018; Gorin et al., 2008). In fact, increases in self-efficacy through vicarious experience may be one explanation for these "ripple effects." Some research has shown that one's romantic partner's self-efficacy is associated with one's own health behavior (in the context of smoking; Berli et al., 2018b), but it is unclear whether this association is mediated through changes in individual's own self-efficacy. Additionally, Warner and colleagues (2018) found that, for dual-smoker couples, partners' successful performance of a health behavior did not affect individual's self-efficacy in the context of smoking cessation. This mixed evidence highlights the need for further research.

\section{Summary}

The health behavior transmission route (Route A) is the most straightforward way in the DHIM through which the agent can affect the target's health behavior. It illustrates how 
intrapersonal factors, such as health beliefs that lead to health behavior change, have the potential to elicit interpersonal effects. Although the intrapersonal links between health beliefs and health behavior are well studied, there is very little evidence regarding whether these links are observed across individuals (Karney et al., 2010) - do changes in an agent's health behavior elicit changes in a target's health beliefs and, if so, do these changes lead to changes in the target's behavior? These questions can be tested in existing evidence-based interventions by collecting belief and behavior change data from the untreated romantic partners of participants.

\section{Route B: Relational Behaviors (How Agent's Relational Beliefs Affect Their Relational Behaviors and Facilitate Change in Target's Health Behavior)}

The behaviors that individuals enact toward their relationship partners can have shortand long-term effects on their partner's health, an idea that has been pursued by health psychologists and relationship scientists alike (e.g., Karney et al., 2010; Robles \& KiecoltGlaser, 2003; Slatcher \& Selcuk, 2017). To date, much of this work has focused on whether and how indicators of relationship quality are associated with downstream health outcomes (Shor et al., 2013; Uchino, 2006). Yet, the ways in which romantic partners unintentionally affect each other's health behaviors remain understudied. In the DHIM, we focus on how the agent's relational behaviors may affect health behavior change (see Route B on the right of Figure 2).

An agent's relational behaviors are actions that the agent engages in that aid the target and/or create a positive relationship with them. These behaviors are enacted without the intention of changing the target's health behavior and are typically informed by agents' relational beliefs. Thus, the second of the three central routes from agent's beliefs to target's health behavior change begins with the agent's relational beliefs, which affect the agent's relational behaviors, and then, in turn, the target's health behavior. We propose that relational behaviors can do this in 
two ways. First, agents can facilitate changes in the target's health behavior by providing support or reducing targets' stress, allowing the health behavior to be more easily enacted. Second, agents can act in ways that uplift the target and cultivate a stronger sense of self-esteem and selfcompassion, which may then facilitate health behavior change in targets. Notably, in this route, agents' relational behaviors do not directly affect targets' health beliefs or health behaviors because agents' behaviors are not enacted to intentionally affect targets' health. We begin by defining agents' relational beliefs and relational behaviors. Then, we discuss what is known - and what research is needed - about how agents' relational behaviors affect targets' health behaviors.

\section{Agent's (and Target's) Relational Beliefs}

Both agents and targets have relational beliefs, but they function differently in the DHIM. The agent's relational beliefs should inform their relational behavior, which may indirectly affect the target's health behavior, whereas the target use their relational beliefs to interpret and respond to the agent's actions. Relational beliefs encompass the agent's or target's beliefs about their relationship, and include constructs such as interdependence, commitment, relationship quality, satisfaction, power, equity/reciprocity, attachment, closeness, and responsiveness. This is not an exhaustive list of relational beliefs that could be applied in the DHIM; rather, it is a list of beliefs that are common across theories from relationship science (e.g., interdependence theory, Kelley \& Thibaut, 1978; Rusbult, 1983; attachment theory, Bowlby, 1969; Mikulincer \& Shaver, 2016; risk regulation theory; Murray et al., 2006). The degree to which relational beliefs complement, overlap with, or conflict with each other remains unclear and work designed to clarify these constructs is ongoing (Finkel et al., 2017). Thus, we recommend that researchers who use the DHIM select a theory or model in relationships science and its related constructs, rather than examine an exhaustive list of relational beliefs. 
As close relationship partners, agents and targets have unique knowledge and beliefs about each other. These beliefs are composed of their perceptions of each other's specific needs and motivations, and their personalities and preferences. The agent should be inclined to tailor their behavior based on these beliefs about the target (Fitzsimons et al., 2015; Simpson \& Overall, 2014), as well as how they perceive the target will respond, think, and feel in response to the agent's behavior.

\section{Agent's Relational Behaviors}

The agent's beliefs about the relationship and the target become visible to the target when they are expressed in the agent's behavior. In the DHIM, relational behaviors are conceptualized according to the agent's intention rather than the target's perception. In addition, they are not undertaken to affect the target's health behavior per se; instead, they are relationship-promoting behaviors that might, over time, unintentionally and indirectly facilitate health behavior change. Finally, because the DHIM describes the determinants of positive health behavior change, only supportive relational behaviors are included in the model. Negative relational behaviors such as criticism and hostility have been shown to be associated with worse health and/or relational outcomes over time (e.g., Klein et al., 2016; Kiecolt-Glaser et al., 2005; 2010; see Meltzer et al., 2013 for an exception). An agent may also act destructively toward a target to change the target's health behavior, but the agent's intention renders these examples influence strategies, which we discuss in the next route.

With their relational behavior, agents may aim to alleviate negative states and prevent negative outcomes (i.e., negative-alleviating behaviors) or promote positive states and outcomes (i.e., positive-promoting behaviors) in targets. Some relational behaviors, for ex ample, can mitigate stress or soothe negative emotions, whereas others can uplift partners, enhance their 
positive affect, or encourage personal growth. Alleviating negative outcomes involves actions such as partner buffering - emotionally or behaviorally regulating one's partner when they are distressed so that they can manage their negative emotions and think and behave more constructively (Simpson \& Overall, 2014). Behaviors that alleviate negative outcomes can also entail providing support, which can be emotional (e.g., giving reassurance), informational (e.g., giving advice), or tangible (e.g., giving time, effort, or money) (House, 1981).

Romantic partners can not only can buffer one another from stressors and emotional distress; they can also encourage each other to approach and pursue positive goals and outcomes. Using positive-promoting behaviors, agents may encourage targets to explore new activities and pursue their most important goals, including health-relevant ones (Feeney \& Van Vleet, 2010). Similarly, agents may respond enthusiastically when targets share good news (i.e., capitalize) with them (Gable et al., 2004), or the agent may affirm the target by eliciting behavior from them that is more closely aligned with the target's ideal self (Rusbult et al., 2005). By expressing confidence and faith in the target, as well as enthusiasm for their pursuits and goals, an agent can uplift the target and encourage their personal growth.

Relational behaviors can also vary in their directness. Directness reflects the extent to which a relational behavior is intended by the agent to explicitly promote the relationship and/or the partner's well-being, such as by complimenting the target and providing visible emotional or instrumental support (e.g., tangible aid) to the target (Biehle \& Mickelson, 2012; Girme et al., 2013; Zee et al., 2018). The intention s underlying the agent's actions, therefore, are clear to the target. Relational behaviors that are indirect can promote the relationship or the partner's wellbeing, but do so in a less noticeable manner. Indirect relational behaviors may, for example, alter 
the relationship environment in a positive way, such as when an agent does extra chores for the target.

\section{Agent's Relational Beliefs $\rightarrow$ Agent's Relational Behaviors (B1)}

There are many ways in which an agent's relational beliefs could lead them to engage in behaviors that support the target or foster a more positive relationship. Relation ship partners who are more interdependent, for example, often have more op portunities to interact and influence each other's outcomes and to engage in positive relational behaviors (see Kelley et al., 1983). Additionally, partners who believe in reciprocity or notice inequity in their relationship may engage in more or fewer positive relational behaviors, depending on the direction of the perceived inequity (Walster et al.1976). Moreover, the agent's evaluations of the target and the relationship with respect to satisfaction or relationship quality should also guide their relatio nal behaviors; with those who feel more positively about the target and their relationship being more inclined to engage in positive relational behaviors (e.g., Murray et al., 1996).

Although agents' beliefs about the relationship should affect the likelihood of engaging in positive behaviors, their beliefs do not determine which positive behaviors they will enact. Instead, agents rely on their beliefs about and knowledge of the target to determine which relational behaviors the target is likely to view positively. For example, agents must consider targets' current (or state) emotions, needs, and desires to decide whether they should prioritize alleviating negative or promoting positive outcomes for targets.

Agents must also be mindful of targets' chronic (or trait) tendencies and motivations. For example, a target's attachment orientation may influence whether the agent chooses to engage in direct or indirect relational behaviors. If, for example, the target has an avoidant attachment orientation (i.e., wants to be self-sufficient, is not comfortable trusting others, and dislikes 
emotional intimacy), the agent may rely on more indirect relational behaviors that are less likely to threaten the target's autonomy (e.g., Overall et al., 2013; Simpson et al., 2007). Yet, some targets respond better to relational behaviors in which care is communicated directly. For example, anxiously attached targets, who are hyper-vigilant about being abandoned and yearn for greater support, desire greater attention and reassurance from their relationship partners.

Consequently, they react more negatively to indirect, instrumental forms of support that do not directly meet their chronic needs (Mikulincer \& Florian, 1997). Agents, therefore, may use their knowledge of what elicits favorable responses from targets to tailor the type and amount of support that they provide.

The Moderating Effect of Agent's Relational Behaviors on the Link Between Target's Health

\section{Beliefs $\rightarrow$ Target's Health Behavior (B2)}

The connection between partners' relational beliefs and relational behaviors has been well-established, whereas the connection between one partner's positive relational behaviors and the other's health behavior change has received little attention. This dearth may seem surprising given that innumerable studies have established links between the quality of one's relationships and one's health, and many researchers acknowledge the need to identify behavioral processes through which positive relationships lead to better health (e.g., Farrell \& Stanton, 2019; KiecoltGlaser et al., 2010; Umberson et al., 2010).

Additionally, many studies have addressed related questions about other relational constructs and health behaviors. For example, both lower relationship satisfaction and greater conflict and relationship dysfunction are associated with engagement in less healthy behaviors in cross-sectional and longitudinal studies (Kiecolt-Glaser \& Newton, 2001; Roberson et al., 2018). Higher relationship satisfaction aids successful smoking cessation (Foulstone et al., 2017), and 
greater closeness with one's partner predicts less drug use during substance abuse treatment (Heinz et al., 2009). Furthermore, people who are married or in a relationship tend to report engaging in healthier patterns of behavior such as drinking less alcohol (Waite, 1995) or complying with regular screening guidelines (El-Haddad et al, 2015; Stimpson \& Wilson, 2009).

These studies demonstrate a clear link between relationships and health behavior, but they usually rely on measures of relational beliefs or relationship status, not relational behaviors. Yet, explanations offered for the observed links between relational beliefs or status and health behavior typically acknowledge that the association is likely to be mediated by other processes, such as relationship partners' actions (e.g., Roberson et al., 2018). We argue that a pattern of supportive and responsive relational behavior can create a context in which it is easier for the target to pursue their health behavior goals, especially those that might prove challenging. Specifically, we propose that there are two primary ways in which agents' relational behaviors could facilitate targets' beliefs-to-behavior link: by reducing targets' stress, and by increasing their self-esteem or self-compassion.

Reducing Stress. Work, finances, discrimination, and low-quality relationships can be sources of chronic stress. Experiencing chronic stress can dysregulate cardiovascular, endocrine, and immune systems, leading to worse health outcomes over time (e.g., Robles, 2014). But how does chronic stress affect health behavior? Greater perceived stress is associated with engagement in less healthy behaviors, such as smoking (Ng et al., 2003) and getting less sleep (American Psychological Association, 2014). When stressed, people also alter their usual health behavior -- they consume foods higher in sugar and fat (Torres \& Nowson, 2007) and also report exercising less when stressed, even though they believe that physical activity is an effective way to reduces stress (American Psychological Association, 2014; Stults-Kohlemainen \& Sinha, 
2014). In one study, individuals in high-stress jobs reported the same intentions to exercise as those in low-stress jobs, but ex ercised less the following week (Payne et al., 2002). Thus, even when individuals hold the requisite health beliefs that should lead to healthy behavior, stress can disrupt their ability to turn their beliefs into action.

Perceived stress can lead to changes in health behavior engagement through the effect of stress on self-regulation (e.g., Baumeister \& Heatherton, 1996), the enactment of unhealthy behaviors (e.g., substance use) as a coping mechanism for stress (e.g., Stress-Coping Theory; Finney \& Moos, 1984; Moos \& Schaefer, 1993), and the way in which managing stressful life events requires time, energy, and resources that might otherwise be used to engage in healthy behaviors. Thus, one way that agents could help targets engage in healthy behaviors is to reduce the amount of stress in targets' lives.

Agents may also enact negative-alleviating relational behaviors to minimize targets' stress, allowing targets to conserve the resources needed to make health behavior change. For example, if a target wants to exercise more but believes they lack the time to do so, the agent may remove this barrier by providing instrumental support (e.g., taking on some of the target's responsibilities, such as watching their children or completing their chores). In addition, the agent could provide tangible support, such as paying for the target's membership at a closer but more expensive gym, saving the target commuting time. Relationships may also prevent exposure to stress in the first place. For example, agents and targets can pool economic resources while sharing living expenses and labor, which may allow them to achieve higher socioeconomic status and prevent financial stress, which is a risk factor for engaging in unhealthy behaviors (Stimpson et al., 2012). 
Agents can also help targets manage stress by providing emotional support. For example, research has revealed that when individuals experience stressors, their partner's negativealleviating behaviors can both ease their anxiety (Collins \& Feeney, 2000; Simpson et al., 1992) and reduce the stress caused by such events (Floyd et al., 2010). Receiving support can also protect targets from the negative effects of stress by enhancing their ability to cope with stressors, both immediately and over time (Lazarus \& Folkman, 1984). Thus, not only can agents' relational behaviors help reduce the occurrence, frequency, or duration of stressful events; agents can also reduce the psychological impact of stressful events that do occur.

With their relational behaviors, the agent may be able to facilitate the connection between the target's own health beliefs and their health behavior by relieving the target of burdens. However, even though research supports that stress can hinder engagement in healthy behavior and that agents can lessen stress in targets' lives, research still needs to establish whether reductions in stress actually cause individuals to implement their health beliefs into behavior.

Increasing Self-Esteem and Self-Compassion. Agents' relational behaviors may cultivate beliefs about the self in targets that allow them to act on their health beliefs. These selfbeliefs ought to include self-esteem and self-compassion, which are related, but distinct constructs (e.g., Neff \& Vonk, 2009). Self-esteem is "an evaluation of our worthiness as individuals, a judgment that we are good, valuable people" (p. 1, Neff, 2011). Self-compassion involves treating oneself with kindness and understanding, recognizing that mistakes are normal and that no one is perfect, and being aware of, but not overwhelmed by, internal thoughts and feelings (Neff, 2003).

Agents can foster these beliefs in targets given that people develop beliefs about their worth based on how others, especially close others, view and treat them (e.g., Garber et al., 1997; 
Leary et al., 1995). As a result, relationship partners who view each other positively may be able to build self-esteem in each other over time (Marigold et al., 2007; 2010; Murray et al., 2000). Similarly, agents can build targets' self-compassion by regularly providing targets "the perspective of an ideally compassionate friend," an instruction that characterizes interventions to develop self-compassion (Neff \& Germer, 2013, p. 33; Smeets et al., 2014). Agents may also communicate positive regard and compassion through positive-promoting relational behaviors, such as complimenting targets and encouraging their growth, or negative-alleviating relational behaviors, such as comforting targets when they feel sad or insecure.

Some of these self-beliefs have been linked with transforming health beliefs into health behavior. For instance, when individuals receive threatening health information, interventions designed to remind them of their self-esteem and what they value (i.e., self-affirmation interventions) allow them to more easily accept the information and act on changing their health behavior (Epton et al., 2015). Similarly, an intervention that invoked positive affect and encouraged hypertensive individuals to self-affirm when they found it difficult to take their medication led to significantly greater medication adherence 12 months later, compared to a control intervention (Ogedegbe et al., 2012). Additionally, Huntsinger and Luecken (2004) found that having a secure attachment style was associated with engaging in healthier behaviors, partially mediated by self-esteem. This study was cross-sectional so the results must be interpreted cautiously, but they support the idea that positive relationships, self-esteem, and healthy behavior are related.

Self-compassion is also positively associated with engaging in health-promoting behaviors in many domains (Biber \& Ellis, 2017; Sirois et al., 2015; Terry et al., 2013). Selfcompassion may also foster resilience and self-forgiveness in the face of health behavior change 
setbacks, such as "cheating" on a diet, reducing the likelihood that a single behavioral lapse will prevent further progress (Semenchuk et al., 2018; Terry \& Leary, 2011). In fact, self-compassion may motivate individuals to improve upon their perceived failures (Breines \& Chen, 2012). Thus, self-compassionate targets whose health beliefs include intentions to change their health behavior may better succeed at doing so, and targets who feel that they, as a whole, are worthy of care may also believe that their health is deserving of care. Ultimately, through their relational behavior, agents may be able to promote self-esteem and self-compassion in targets, and these revised self-beliefs might then assist targets in enacting their health beliefs.

To date, little longitudinal or intervention research has examined whether and how romantic partners affect each other's self-esteem and self-compassion over time. A recent review revealed that self-compassion is positively associated with attachment security, positive relationship functioning, and constructive conflict behavior, but these associations are likely to be bidirectional, so there is need for more longitudinal and intervention work to determine causality (Lathren et al., 2021). Similarly, research on self-esteem and romantic relationships has demonstrated correlational links between high quality relationships and self-esteem (e.g., Denissen et al., 2008), but less research has examined whether changes in relationship quality or behavior cause changes in self-esteem, and these associations are likely to be bi-directional, as well (e.g., Mund et al., 2015). Research that examines whether romantic partners can change each other's self-compassion and self-esteem is therefore needed.

\section{Promising Research Directions for Route B}

One of the objectives guiding the DHIM is a focus on positive intention by the agent. The DHIM assumes that the agent is motivated to cultivate and maintain a positive relationship with the target and wants good outcomes for the target. Nevertheless, romantic partners can engage in 
positive relational behaviors that have negative consequences for the target's health behaviors. For instance, agents can have a goal to increase closeness with the target, but the activities that increase closeness may involve unhealthy behaviors. For example, an agent may see that their partner is stressed and then suggests they enjoy a large bottle of wine together that evening. The agent's behavior may be motivated by the positive relational goal of helping reduce the target's stress, but the chosen activity increases the likelihood that the target will engage in an unhealthy behavior.

These ideas provide one explanation for why people often experience weight gain when they enter romantic relationships (Dinour et al., 2012; Sobal et al., 2003). One study of friends found that indulging in ultra-processed, high-calorie foods (e.g., sweets, salty snacks, or "friend foods") not only occurs more frequently in close relationships, but also results in stronger feelings of closeness (Cummings \& Tomiyama, 2019). Research has also found that women are more likely to be influenced by the eating patterns of their partn ers when they are motivated to form relationships, whereas men are more likely to be influenced by the eating pattern s of their partners when they are motivated to maintain relationships (Hasford et al., 2018). Research in other health domains, such as sexual behavior, has revealed that relationship-relevant motivations affect decision-making about condom use, such that people who are more motivated to increase closeness and commitment are less likely to request or use condoms (Skakoon Sparling \& Cramer, 2019; Umphrey \& Sherblom, 2007). Taken together, current evidence suggests that romantic partners can negatively affect each other's health behavior in the service of positive relational goals. Future research should test this prediction in other health domains.

Social Support. Any discussion of relational behaviors and health necessitates the mention of social support. Linkages between social support and health have been widely studied 
(e.g., Berkman et al., 2000; Cohen \& Syme, 1985; Heaney \& Israel, 2008; House et al., 1988;

Shumaker \& Hill, 1991; Uchino, 2006). Despite (and perhaps because of) its popularity, social support has been conceptualized in so many different ways that the concept is amorphous. Operationalizations of it range from measuring helpful behaviors provided by a specific person (Koestner et al., 2012; Maisel \& Gable, 2009) to broader beliefs that people within one's social network will provide aid in times of need (Shor et al., 2013; Uchino, 2009). Furthermore, relational behaviors and influence strategies are often conflated in social support measurement, which limits investigators' ability to determine which interpersonal processes drive effects and how to intervene on such processes. For instance, in DiMatteo's (2004) meta-analysis of the effects of social support on adherence to medical treatment, practical support measures included general receipt of help from close others, support for engaging in the relevant health behavior, and nagging to engage in the health behavior. To complicate matters, emotional support is sometimes measured generally and sometimes specifically with regard to a specific health behavior or issue. Therefore, it is not clear whether the support was provided in relation to the health behavior, or whether it was enacted to benefit the relationship, modify the target's health behavior, or some mixture of these (or other) motivations. In the DHIM, we distinguish between these two kinds of behaviors - relational behaviors and influence strategies, which are likely to be informed by different sets of beliefs and may differ in how they affect targets. Researchers can use these distinctions to inform both their measurement of relational behaviors and influence strategies and their interventions that target these behaviors.

\section{Summary}

Within the relational route of the DHIM (Route B), we have highlighted how agents can have an impact on targets' health behaviors through their relational beliefs and actions, without 
intentionally trying to change the target's health behavior. Agents' relational beliefs inform their relational behaviors (negative-alleviating vs. positive-promoting and direct vs. indirect) toward the target. Agents' relational behaviors affect the target's relational beliefs, which, in turn, affect their relational behaviors and relationship outcomes. Agents' relational behaviors can also moderate the association between targets' health beliefs and health behaviors by affecting targets' experiences of stress and targets' self-esteem and self-compassion.

Given that most relationship partners care about and want what is best for each other, they may also monitor each other's health status and, at times, deliberately try to influence and improve each other's health behaviors. Accordingly, we now discuss the third major route in our model - how and why agents may, at times, intentionally attempt to influence targets to change specific health behaviors and how, in doing so, they must balance concerns about maintaining the quality and stability of their relationship with concerns about how to promote their partner's long-term health outcomes.

\section{Route C: Influence Strategies (How Agent's Beliefs About Target's Health and Agent's Relational Beliefs Affect the Use of Influence Strategies and Elicit Change in Target's Health Beliefs and/or Health Behavior)}

The third major route in the DHIM focuses on the use of influence strategies (see Route $\mathrm{C}$ in the center of Figure 2). The agent's beliefs about the target's health, as well as the agent's relational beliefs, underlie the agent's motivation to enact different influence strategies. In deciding how to act, agents will likely have predictions about how the target will respond to the agent's behavior, both relationally (e.g., Will my partner be angry at my direct influence attempt to help them lose weight?) and with regard to their health behavior (e.g., Will my partner comply and change their eating or exercise behavior?). Moreover, once the agent acts, the target may 
update their relational beliefs based on the agent's behavior. The influence strategies that are used may generate immediate or gradual changes in the target's specific health beliefs and/or health behavior. This path, therefore, emphasizes how relationship and health beliefs are both important in shaping and being shaped by the social exchange processes that exist between the agent and the target, which have implications for not only the target's health, but their relationship as well.

\section{Agent's Beliefs about Target's Health}

Similarly to how an agent has beliefs regarding their own health behavior (e.g., self efficacy, norms, risk appraisals), they also harbor beliefs regarding the target's health behavior. For example, the agent may also hold beliefs about the target's social norms (e.g., "My partner has few close friends that exercise regularly.”). Only a few studies to date have examined agents' beliefs about targets' health in the context of romantic relationships. Howland and colleagues (2016) expanded the Theory of Planned Behavior to include individuals' reports of attitudes, norms, and perceived behavioral control about their partners' health behavior. Sullivan and colleagues (2010) assessed agents' perceptions of their spouses' readiness to change their health behaviors using the Transtheoretical Model of Change (Prochaska \& Velicer, 1997). Agents can also hold health meta-beliefs that reflect what they (agents) think targets believe about their health. An agent, for example, could hold a meta-belief about the target's risk appraisals (e.g., "My partner believes that they are at low risk for poor health outcomes"), or about the target's self-efficacy (e.g., "My partner thinks that they are incapable of exercising"). The agent's metabeliefs reflect a type of mind-reading in which the agent tries to anticipate the target's viewpoint (e.g., Carlson, 2016). The agent's meta-beliefs are distinct from their beliefs about the target's health, which reflect the agent's own beliefs about the target. Meta-beliefs are important because 
the agent can compare their beliefs about the target's health to what they think the target believes, note discrepancies, and then adjust their influence behavior accordingly.

Promising Research Directions. A large body of empirical and theoretical work has delved into the conceptualization, measurement, and distinctions between different health beliefs at the intrapersonal level. Researchers, for instance, have not only identified risk perceptions as an important health belief, but have made fine-grained distinctions between different components of risk perceptions (e.g., Ferrer et al., 2016). In contrast to the vast amount of research that has focused on intrapersonal health beliefs, minimal work has focused on interpersonal health beliefs (but see Ghassemi et al., 2020; Klein \& Ferrer, 2018), despite their potential utility for understanding how romantic partners influence each other's health behavior.

One promising future research direction is to transform existing measures of individual health beliefs into interpersonal health beliefs (see Howland et al., 2016). For example, measures of risk perceptions about the self could easily be transformed into risk perceptions about one's partner. Additionally, one could explore features of these beliefs, such as the strength of agents' beliefs about targets' health and how facets of these beliefs change over time. Agents may have weaker or less coherent beliefs about targets' health early in the relationship compared to later. Thus, relationships may need to exist for a certain period of time before agents are sufficiently confident to act on their beliefs about their partners' health. Agent's Relational Beliefs $\rightarrow$ Agent's Beliefs about Target's Health (C1)

An agent's relational beliefs should inform the beliefs they hold about the target's health, including their type, strength, and complexity. Given that highly interdependent romantic partners have more to lose if their partner becomes sick or dies, they should be more motivated to formulate a plan to promote their partner's health compared to less interdependent partners. 
Thus, to the extent that an agent is interdependent and committed to their relationship with the target, they may be more likely to develop beliefs about the extent to which the target is at risk for different health problems. Additionally, as an agent and target spend more time together, agents have more opportunities to learn about the target's healthy or unhealthy behavioral practices. Despite the intuitiveness of these predictions, we were unable to find any research that has directly examined whether an agent's relational beliefs impact their beliefs about the target's health in the context of romantic relationships.

Promising Research Directions. One direction for future research is to examine whether changes in an agent's commitment to the relationship are associated with changes in how they construe their attitudes toward the target's health behavior. For instance, early on in a relationship, an agent may hold only abstract favorable beliefs about the target's behavior and may not be particularly motivated to attend to the target's behavior. However, with growing commitment to the relationship, the agent may develop a more articulated set of beliefs about the target's behavior, recognizing what the target cares about (e.g., "My partner values regular exercise") and what they believe the target ought to care about (e.g., "My partner doesn't appreciate the importance of a healthy diet").

Longitudinal studies that follow couples soon after relationship initiation could test these predictions by examining how an agent's attitudes about the target's health behaviors develop and change as the agent becomes more committed to target. Furthermore, understanding the connection between an agent's relational beliefs and their beliefs about the target's health would be fruitful for intervention research and for our theoretical understanding of cognitive changes in relationships. If an agent's commitment, for example, is associated with their beliefs about the 
target's health and these beliefs shape their behavior toward the target, this information could help interventionists identify the sample for whom their intervention would be most effective.

\section{Influence Strategies}

Close relationships are characterized by the enduring, mutual influence that partners have on one another across time and social contexts (Kelley et al., 1983). The social influence route in the DHIM focuses on conscious, intentional influence attempts enacted by the agent and directed toward the target. We define influence strategies as sets of behaviors (i.e., persuasion tactics) enacted by the agent with the intended goal of changing the target's health behavior to be consistent with the agent's beliefs regarding what the target's health behavior should be.

Guided by research on social influence tactics (e.g., Cialdini \& Trost, 1998; Cialdini \& Goldstein, 2004; Cialdini \& Griskevicius, 2010), researchers in social psychology, relationship science, health psychology, and communication have conducted a sizable body of research on the use of influence strategies and specific tactics (e.g., Lewis \& Butterfield, 2007; Lewis \& Butterfield, 2005; Overall et al., 2009; 2013; Overall \& McNulty, 2017). However, influence strategies need to be conceptualized and measured keeping both health- and relationship-relevant factors simultaneously in mind. These efforts remain largely siloed from each other, with limited integration of theories and constructs from relationship science and health behavior change.

For instance, building on research on communication strategies used in problem-solving interactions, Overall and colleagues (2009) developed a taxonomy of communication strategies organized around valence (positive vs. negative) and directness (direct vs. indirect). This typology was developed in the context of romantic relationships in which partners were using communication strategies to produce desired changes in each other (which could have included health behavior change). To date, this typology has been mapped to relationship-relevant 
predictors (e.g., attachment orientations; Jayamaha et al., 2016; Overall et al., 2013) and interpersonal outcomes (e.g., relationship evaluations; Hira \& Overall, 2010; Overall \& Fletcher, 2010), but has not been applied to health behavior change outcomes.

Researchers examining influence strategies with the intended goal of producing changes in health behavior (often referred to as "social control”; Lewis \& Rook, 1999) have also developed taxonomies of influence strategies that have been widely used to understand how relationship partners try to change each other's health behaviors (e.g., Lewis \& Butterfield, 2005; Butterfield \& Lewis, 2002; Lewis et al., 2004). Most researchers applying these taxonomies, however, have not explicitly accounted for relationship-relevant predictors or outcomes, instead focusing on how these strategies affect health behavior change or targets' emotions (Craddock et al., 2015). Viewed together, these lines of work highlight the need for an integrated conceptualization of influence strategies that recognizes both relationship-relevant and healthrelevant predictors of their use and effectiveness.

In sum, there is a need to develop measures of influence strategies that account for both relational goals and relational consequences and for health goals and health consequences. Although developing a new measure of influence strategies is beyond the scope of this paper, we believe an integration of prior work in relationship science and health psychology suggests two productive ways to distinguish between influence strategies: (1) autonomy supportive vs. autonomy limiting, and (2) direct vs. indirect.

Influence strategies can be differentiated along a continuum that ranges from autonomy supportive to autonomy limiting. This reflects the extent to which an influence strategy is intended by the agent to bolster the target's autonomy regarding a given health behavior (autonomy supportive) versus the extent to which it is intended to limit the target's autonomy 
regarding the health behavior (autonomy limiting). Influence strategies that are highly autonomy supportive are those in which agents offer advice or encouragement to targets to engage in a health behavior but leave the decision about how to enact the behavior with targets. Examples include agents offering to engage in the behavior with the target or complimenting the target when they make healthy choices.

Influence strategies that are highly autonomy limiting are those that constrain the target's behavioral decisions or apply pressure on the target to think, feel, or behave in a specific way. Examples include an agent's attempt to persuade targets to change their behavior by focusing on how the target's behavior could harm them (e.g., saying to a smoker, "Smoking causes cancer"), eliciting negative affect (e.g., guilt) from the target when they do not engage in the health behavior, or changing the target's environment in ways that constrain their beha vioral choices (e.g., removing all ice cream from the house, purchasing healthy foods). Autonomy supportive and autonomy limiting behaviors are represented in both the relationship and health literatures in the context of Self Determination Theory (SDT; Deci \& Ryan, 2000) and also regarding the management of chronic illness in close relationships (Martire \& Helgeson, 2017). However, autonomy supportive and autonomy limiting behaviors have rarely been explicitly tied to social influence (but see Dailey, 2018 for examples of how constructs from SDT have been integrated into conceptualization and measurement of influence strategies).

Influence strategies also vary in the degree to which they operate directly or indirectly. Directness reflects the extent to which an influence strategy is intended by the agent to address the health behavior openly, clearly, and explicitly (e.g., Lewis et al., 2004; Lewis \& Butterfield, 2007). Influence strategies that are direct include agent behaviors such as telling the target to change the behavior or asking them if they have taken the necessary steps to change it. Influence 
strategies that are indirect in the DHIM are those in which the agent addresses the health behavior but does so by modifying the context in which the behavior is performed or enacted. This can include displaying nonverbal gestures (e.g., rolling one's eyes or hugging the target) when the target either engages in or does not engage in the desired behavior, giving the target space and showing patience as the target tries to change their behavior, or engaging in the behavior with the target. Agents may also consider the directness of the influence strategy they choose to enact if it could affect targets' relational and health behavior reactions, as we discuss later. Directness and indirectness are represented in the relationship and health literatures in the context of health-related social control (Butterfield \& Lewis, 2002) and partner regulation communication strategies (e.g., Overall et al., 2006). Directness is also related to the construct of invisible support, which is defined as supportive behaviors that are provided by the agent but are not perceived by the target (e.g., Bolger et al., 2000). However, they have not been studied as the product of both relational and health beliefs, nor have the relational and health behavior consequences of such behaviors been examined simultaneously.

\section{Agent's Beliefs about Target's Health and Agent's Relational Beliefs $\rightarrow$ Agent's Influence}

\section{Strategies (C2 and C3)}

How, then, do agents determine what kinds of influence strategies to use? Why, for example, might agents decide to use influence strategies that might yield less positive health or relational outcomes? The literature on these choices is rather limited as prior research has focused on which strategies agents report having used (e.g., Butterfield \& Lewis, 2002; Tucker \& Anders, 2001) rather than on agents' motivations for using specific strategies. In particular, little is known about how agents' relational beliefs and their beliefs about targets' health may jointly affect whether an agent chooses to enact influence along with the specific influence 
strategies and behavioral tactics the agent employs. In this section, we briefly review what is known about the relational beliefs and health beliefs associated with the use of different influence strategies and then use the DHIM to generate predictions to inform future research.

\section{How do agents' beliefs about the targets' health affect agents' use of influence}

strategies? In the context of romantic relationships, studies have found that agents report various health-related reasons for using certain influence strategies, such as wanting the target to eat healthier (Butterfield \& Lewis, 2002; Tucker \& Anders, 2001), lose weight (Tucker \& Anders, 2001), or improve their health or lifestyle (Burke \& Segrin, 2017). Studies have also shown that romantic partners of ten have shared health goals that motivate their use of influence strategies (Burke \& Segrin, 2017; Dailey et al., 2021). One study found that health-compromising behaviors and behaviors that have more severe health consequences are associated with greater use of influence strategies by agents (Lewis \& Butterfield, 2005). Although this research provides evidence that (a) agents have health-relevant motivations that affect their use of certain influence strategies and (b) features of the health issue affect agents' enactment of influence strategies, there is a need for research to map the range of beliefs that agents have about targets' health (e.g., risk perceptions; self-efficacy) that do and do not inform the use of influence strategies. To what extent are an agent's beliefs about a target's health risk a key source of motivation to act and, if so, is there reason to expect that, to be effective, these perceptions must be accompanied by confidence in the target's ability to engage in the necessary behavior (cf. Tannenbaum et al., 2015)

\section{How do agents' relational beliefs affect their use of influence strategies? A few} studies have examined how agents' relational beliefs affect their use of influence strategies, although these strategies rarely have health behavior change as the sole or even primary goal of 
the agent. One individual difference construct grounded in relational beliefs, attachment orientations, has been shown to be associated with influence strategies, such that individuals high in attachment anxiety (those who continually worry about receiving deficient love and support from their romantic partners) use more negative-indirect influence strategies (e.g., guilt induction) than individuals low in attachment anxiety, who tend to be more securely attached (Jayamaha et al., 2016). This study conceptualized influence strategies as "partner regulation strategies," which could apply to a multitude of behaviors that the agent wants the target to change. However, there is a need for research examining how different types of relational beliefs - such as commitment, investment, and power - affect the use of different influence strategies.

Promising Research Directions. How do agents' beliefs about targets' health and agents' relational beliefs jointly affect agents' use of influence strategies? To date, research has not addressed this question. Both types of beliefs should be important determinants of influence strategies, which could be leveraged in dyadic health behavior change interventions. If theory and research focus only on health-relevant beliefs as motivators of influence, it becomes difficult to understand why an agent would use strategies that are less effective in producing desired behavior change (but that are more beneficial for the relationship). Similarly, if theory and research focus only on relational beliefs as motivators of influence, it becomes difficult to understand why agents use influence strategies that create conflict in the relationship (but that are more effective in producing timely behavior change).

The extent to which the agent feels motivated to use influence strategies should be driven, in part, by their perceptions of the target's risks associated with the health issue and agents' perceptions of whether their relationship can withstand any conflict that might occur following the use of influence strategies. If, for example, an agent perceives that the target is at 
high risk for developing skin cancer, they should be more motivated to use influence strategies aimed at improving the target's sun safety behaviors. However, the agent's perceptions of the target's commitment to the relationship should also affect the agent's use of influence strategies, with the agent being less likely to exert influence if they perceive the target's commitment to the relationship is low or that the influence attempt might result in conflict. Accordingly, when agents perceive that the target is at high risk of skin cancer, but the target is not very committed to the relationship, agents should be less likely to enact influence strategies, or they might use influence strategies that are autonomy supportive and/or indirect.

In contrast, when agents perceive that the target is at high risk of skin cancer, but the target is highly committed to the relationship, agents may be especially inclined to use influence strategies, and may turn to those that are autonomy-limiting and/or direct. This prediction has some empirical support; one study of couples in which one partner was being treated for cancer found that although agents anticipated negative reactions to their use of autonomy-limiting influence, they enacted this type of influence strategy anyway, because they perceived it as necessary for the target to survive (Badr et al., 2015). Notably, this study did not examine the relational beliefs that affected agents' use of influence, and it focused on a serious health issue. In the context of a health behavior with less severe consequences, such as oral hygiene, the agent may not consider the relational costs of pursuing direct influence to be worth the benefits afforded by changing the target's behavior.

Understanding how relational beliefs and health beliefs interact to affect an agent's use of influence strategies could facilitate the development of behavioral interventions that target influence processes between partners. For instance, if researchers find that agents who perceive that their partner is at higher risk are more likely to use influence strategies, interventionists 
could develop communications that emphasize the risk to one's partner. Given that individuals may have biases that preclude them from acting on their own health risks, partner-focused risk messages might be a more effective way to produce behavior change via the agent's use of influence strategies. And, if researchers find that certain relational beliefs moderate the association between risk perceptions of one's partner and one's own use of influence strategies, researchers could target the intervention to couples that hold those beliefs. Interventions that focus only on changing an agent's beliefs about the target's health may be ineffective if they do not also consider the agent's relational beliefs because agents may enact influence only when they believe the target's health is at risk and believe the target is committed to the relationship. This example highlights how the DHIM might be used to inform interventions that have the potential to improve health without incurring costs to relationships. Agent's Influence Strategies $\rightarrow$ Target's Relational Beliefs $\rightarrow$ Target's Relational Behavior (C4)

Another important path involves the potential effect that an agent's use of specific influence strategies may have on the target's beliefs about the agent or the relationship, including their corresponding relational behavior. To our knowledge, no research has examined how influence strategies affect a target's relational behaviors through changing their relational beliefs. Some research, however, has investigated how influence strategies in general (i.e., those not directed toward a specific health behavior) are related to targets' relational behaviors. Additionally, some research has examined how influence strategies are associated with targets' relational satisfaction and emotional responses.

How do agents' use of influence strategies affect targets' relational beliefs? There is some evidence linking the use of different influence strategies with targets' relationship 
satisfaction or relationship quality. Novak and Webster (2011) found that on days when agents used instrumental (e.g., intentionally modeling healthy behavior, planning meals with the target) or reinforcing strategies (e.g., verbal encouragement, praise), targets reported being more satisfied with their relationship. In another study, agents who reported using more negative strategies in the past six months had partners (targets) who reported lower relationship satisfaction, whereas the use of positive strategies was only marginally positively associated with targets' relationship satisfaction (Young et al., 2019).

Other studies have explored whether relationship satisfaction or quality moderates the association between influence strategies and targets' health behavior change (which we discuss in Section II). However, there is a need for research that examines relational beliefs as an outcome of agents' influence strategies, rather than only a moderator of the link between influence strategies and targets' health behavior change. There also is a need for research that examines relational beliefs other than relationship satisfaction or quality, such as the degree of interdependence, commitment, and perceptions of partner (agent) responsiveness.

A considerable number of studies have investigated how agents' use of influence strategies affects targets' emotional responses. Such studies generally indicate that positive strategies are associated with positive emotional responses and negative strategies are associated with negative emotional responses (Craddock et al., 2015). Okun and colleagues (2007), for instance, found that targets who report their romantic partner use s positive influence strategies are more likely to experience positive emotions as a result (e.g., feeling appreciative), whereas targets who report their partner uses negative strategies are more likely to experience negative emotions (e.g., feeling resentful). Another study of same-sex and opposite-sex couples found that women married to men are least likely to appreciate influence attempts coming from their 
spouse, whereas women married to women are most likely to appreciate spousal influence, though this study did not distinguish between different kinds of influence strategies (Umberson et al., 2018). Although it is possible that targets' emotional responses to social control could be associated with their relational beliefs, research to date has not made a distinction between the emotions that a target experiences and their emotions or beliefs toward their partner (the agent). Thus, the existing empirical evidence suggests that there is a link between agents' use of social control and targets' relational beliefs, but there is a need for research that assesses a wider range of relational beliefs.

\section{How do agents' use of influence strategies affect targets' relational behaviors?}

According to the DHIM, a target can respond to an agent's behavior in ways that are positive, such as showing appreciation or affection, or negative, such as responding with criticism or contempt. This is distinct from how we conceptualize agents' relational behaviors in the DHIM. In the DHIM, we do not include agents' negative or destructive relational behaviors because the DHIM operates under the assumption that agents have positive intent in their relational behaviors. However, targets can have positive or negative relational responses to agents' behaviors. The target's relational behaviors can also be direct or indirect, based on how clearly and actively the target communicates their reactions to the agent's behavior (Rusbult et al., 1986). For instance, the target can directly thank the agent for their support (direct and positive) or criticize the agent for trying to manipulate them (direct and negative). If the agent acts insensitively, the target can withdraw affection from the agent (indirect and negative) or show patience (indirect and positive). The target's relational behaviors should then inform the agent's health and relational beliefs across time. 
To our knowledge, only one study has examined how different influence strategies affect targets' relational behaviors. Huelsnitz and colleagues (2021; Under Review) found that on days when agents engaged in at least one autonomy-supportive influence attempt, compared to none, targets reported engaging in more constructive than destructive relational behaviors toward the agent. There were no associations, however, between agents' use of autonomy-limiting influence attempts and targets' relational behaviors. Targets' emotional reactions to influence were not assessed but may have contributed to their relational behavior. Distinguishing between how agents' use of influence strategies affects targets' relational behaviors compared to their emotional experiences will be important for future research. For example, if a target feels a negative emotion but does not change their behavior toward the agent, the agent will not receive cues that an influence strategy is unwanted and may continue to use it.

Relationships researchers have investigated how communication strategies that could be used to change a partner's behavior have consequences for relational behavior (e.g., Overall, 2020). For instance, receiving higher levels of negative-direct behavior from a partner is associated with increasingly severe relationship problems, especially when partners consistently engage in negative-direct behaviors (Overall, 2020). This study and other work in this area could be utilized as a springboard to better understand how influence strategies affect relational behaviors. Additionally, although studies in the relationship domain have examined the effects of different kinds of communication strategies on relationship satisfaction and relationship problems, how these agent behaviors impact target behaviors in ways that change relationship satisfaction or conflict remain unclear. Accordingly, there is a need for research that (a) specifically focuses on health-related influence strategies, and (b) examines how agents' influence strategies affect targets' relational behaviors directly. 
Promising Research Directions. Given that a considerable amount of research has examined linkages between agents' influence strategies and targets' emotional responses, one next step is to extend this thinking to targets' relational beliefs and behavior. Research investigating how autonomy-supportive and autonomy-limiting strategies are associated with daily changes in targets' relational beliefs and behavior could clarify the long-term relational consequences of influence strategy use. One prediction rooted in self-determination theory (Deci \& Ryan, 1985; Knee et al., 2013; La Guardia \& Patrick, 2008) is that an agent's use of influence strategies that are highly autonomy-supportive are likely to evoke more positive relational beliefs in targets because such strategies communicate that the agent wants to bolster the target's selfsufficiency with regard to a valued health behavior. Individuals who feel more autonomous in their relationship report greater relationship satisfaction (e.g., Knee et al., 2005) and individuals who experience greater need fulfillment report better post-conflict relationship quality (Patrick et al., 2007). Thus, to the extent that an agent uses autonomy-supportive strategies, the target should respond with positive changes in their relational beliefs and positive relational behaviors.

In contrast, influence strategies that are highly autonomy-limiting may signal that the agent does not respect or trust the target's self-sufficiency concerning their health behavior, which could engender negative emotions, such as anger, in the target. The target's anger would correspond with their cognitive reaction, that the agent was insen sitive, thus having a negative impact on the target's relational beliefs. More immediately, the target's negative relational beliefs that result from the agent's influence attempt may produce reactance, resistance, and anger in the target, prompting them to act negatively towards the agent. Particularly if the target's negative reaction is direct, the relationship between the agent and target might suffer. These findings would be especially informative for understanding the effects of influence 
strategies over time and whether or not some influence strategies are more versus less likely to facilitate desired change over time. Additionally, influence strategies that induce negative relational behaviors from targets may be less likely to be enacted by agents due to the negative relational consequences they could incur. Dyadic interventions designed to increase the use of strategies that have negative relational consequences would probably be less successful than interventions that increase the use of strategies that have neutral or positive effects on targets' relational beliefs and behaviors.

\section{Agent's Influence Strategies $\rightarrow$ Target's Health Beliefs (C5) and Health Behavior (C7)}

The specific influence strategies used by agents should not only predict changes in the target's relational beliefs and behavior, but also changes in or maintenance of the target's health beliefs and/or behavior. As discussed earlier, one health-relevant goal underlying agents' use of influence strategies is to change targets' health beliefs. To date, research has examined the conditions under which agents' use of specific influence strategies predicts changes in targets' health behavior (e.g., Craddock et al., 2015), but has not investigated whether influence strategies lead to changes in targets' health beliefs (which in turn may result in changes in targets' health behavior). We examine each of these potential outcomes in turn.

Although research has not examined the link between agents' influence strategies and targets' health beliefs in the context of romantic relationships, predictions regarding which strategies may be more influential can be generated using existing research on communication and health belief change. Meta-analytic evidence has shown that changing individuals' (targets') self-efficacy has medium-sized effects on health behavior change (Sheeran et al., 2016). In the context of increasing physical activity, this work has identified several effective strategies to increase self-efficacy, including providing feedback on an individual's past performance of a 
behavior or others' performance (Ashford et al., 2010) as well as vicarious experiences (i.e., watching someone successfully complete a task), verbal persuasion, and emotional arousal (Rajati et al., 2014). In the context of dietary behaviors, effective strategies include self monitoring of dietary behavior, providing feedback on performance, prompted review of behavioral goals, and planning for social support, all of which increase dietary self-efficacy (Prestwich et al., 2014). These are merely two behavioral contexts, but they are two frequently mentioned areas of desired behavior change by romantic partners (agents) (Lewis \& Butterfield, 2007).

Romantic partners are particularly well-suited agents of change for targets'self-efficacy for several reasons. First, partners (agents) are more likely to have information on targets' past behavioral performance, thereby enabling them to provide feedback on that performance, which could subsequently increase targets' self-efficacy. Second, if agents live with the target, they should have more opportunities to engage in behavioral modeling, which can offer opportunities for vicarious experience for targets, which in turn could increase their self-efficacy. Finally, partners are likely to have relational motivations that may increase their use of influence attempts to induce behavior change in their partner.

Romantic partners can also engage in behavioral modeling as an influence strategy, which can provide vicarious experiences for targets. Behavioral modeling (e.g., an agent starts a morning walking routine with the intention of motivating the target to be more active) can be construed as an autonomy-supportive, indirect strategy. It is important to note that behavioral modeling can be used either intentionally as an influence strategy (the influence strategies route; Route C) or unintentionally (the health behavior transmission route; Route A). Strategies that are more indirect may be an effective way to change the target's self-efficacy if they are not 
perceived as influence attempts by the target (i.e., invisible influence strategies). Indeed, invisible support and invisible control are associated with health behavior change (e.g., Lüscher et al., 2019; 2015;2014), and targets' self-efficacy is a strong candidate for an intrapersonal mediator. In contrast, strategies that are more direct may be needed to change the health beliefs that underlie instrumental health attitudes (e.g., "Exercise is good for me because it has health benefits").

Most research that has investigated the impact of influence strategies has focused on the distinction between positive and negative influence strategies, finding that the use of positive strategies is associated with behavior change and the use of negative strategies is either weakly associated or unassociated with behavior change (Craddock et al., 2015). However, the absence of evidence regarding whether belief change underlies the effect of influence strategies on behavior change limits the conclusions that can be drawn. To the extent that agents can change targets' behavior without needing to change their beliefs, agents could utilize strategies that focus on altering a targets' environment (an influence strategy that is more autonomy-limiting). For example, an agent could consistently buy food or prepares meals for a target that support the goal of increasing the target's vegetable intake, regardless of whether the target changed their beliefs about doing so. These indirect influence strategies may be more effective than direct ones particularly when the agent has more control over a target's structural environment or more power in the relationship. However, reliance on these strategies may have adverse effects on the target's relational beliefs, especially to the extent that the target feels manipulated or powerless. Although on the surface these processes can appear similar to those that underlie the behavioral transmission route, within the current path, the agent performs the behaviors with the explicit intention to induce health behavior change. 


\section{Moderating Effects of Agent's Influence Strategies on Link between Target's Health Beliefs}

\section{$\rightarrow$ Target's Health Behavior (C6)}

Given that research has not directly examined how agents' influence strategies affect targets' health beliefs, it is not surprising that research has not examined how agents' influence strategies moderate the association between targets' health beliefs and health behavior. Instead of aiming to alter the target's health beliefs, an agent could also use influence strategies to strengthen the link between the target's health beliefs and their health behavior. This might involve changing the target's environment to make the behavior change easier to accomplish or providing prompts or reminders about the need for behavior change. Several health behavior change theories, in fact, highlight the barriers and benefits afforded by one's environment as key factors in promoting behavior change (e.g., social cognitive theory, Bandura, 1997). If, for instance, a target wants to start exercising but feels intimidated going to the gym alone (a psychosocial barrier), the agent could go along until the target becomes comfortable, thereby facilitating the beliefs-to-behavior connection. Likewise, if a target believes it is important to receive screening for breast cancer but does not know at which age they should begin getting mammograms, the agent could offer to find this information.

Agent's Influence Strategies $\rightarrow$ Target's Relational Beliefs $(C 4) \rightarrow$ Target's Health Behavior (C8)

Agents may also use influence strategies designed to change the target's relational beliefs with the goal of changing the target's health behavior. Favorable relationship beliefs may lead targets to change their health behavior despite the fact that they have unfavorable attitudes toward the behavior or perceive themselves to be at low risk for a health problem. For example, if an agent evokes relationship-relevant thoughts, such as the target's commitment to the 
relationship or the importance of reciprocity, the agent might be able to induce health behavior change in the target. In this case, the target may go the gym regularly, eat a healthier diet, or undergo cancer screening, not because they want to or feel they should, but because of their affection for their partner. This might be especially true if the target expects that doing so will please their partner or lead the agent to become more committed to the relationship.

Promising Research Directions. Although these ideas have not been tested directly, research on we-talk and shared goals in the context of health behavior change in romantic relationships could be a promising direction for future work. "We-talk" is typically examined in research on the use of first-person plural pronouns in conversations (e.g., Karan et al., 2019), but it can also reflect the interdependence and transformation of motivation processes that occur in romantic relationships (Lewis et al., 2006; Rusbult \& Arriaga, 1997; Rusbult \& Van Lange, 1996). Meta-analytic work has shown that one's own as well as one's partner's we-talk is associated with better relationship functioning and healthier behaviors (Karan et al., 2019). For instance, pre-treatment we-talk (e.g., describing smoking as "our" problem rather than “my/your" problem") is associated with greater smoking cessation at 1-year follow-up (Rohrbaugh et al., 2012).

Similar ideas could be applied in the context of agents' influence strategies affecting targets' relational beliefs and their health behavior change. For example, a couples' intervention could focus on changing how agents talk to targets about the health issue about which they are concerned (i.e., a verbal influence strategy). Rather than conceptualizing a health issue and talking about it as the target's problem, the agent's conceptualization of an issue as "our" problem could induce or create more positive relational beliefs in targets (e.g., the agent cares for the target and is committed to them), thereby motivating targets to engage in the health behavior. 


\section{Summary and Conclusion}

Route $\mathrm{C}$ in the DHIM illustrates how an agent's health beliefs about the target, along with their beliefs about the relationship, can both contribute to their decision to e nact influence strategies (or refrain from doing so) and which kinds of influence strategies to employ. Whereas most research on influence strategies has primarily focused on describing the kinds of influence strategies agents use, as well as their effects on target's health behavior and affective responses, the DHIM considers health-relevant and relationship-relevant precursors to the agent's decision to use different influence strategies and their effects on health-relevant and relationship-relevant behavioral responses from the target. This route highlights the importance of considering healthrelevant and relationship-relevant beliefs and goals when considering the causes and consequences of enacting specific influence strategies.

Together, the health behavior transmission route (Route A), the relational behaviors route (Route B), and the influence strategies route (Route C) reflect the three central routes through which the health and relational beliefs of one partner (the agent) can affect the health and relational behaviors of the other partner (the target). Next, we turn to a key moderator of the influence strategies route - targets' relational beliefs.

\section{Section II: Target's Relational Beliefs: A Key Moderator of the Effects of the Agent's Influence Strategies on the Target's Health Beliefs and Behavior}

The target's relational beliefs provide a critical context in which the agent's influence strategies operate. Thus, in Section II, we propose ways in which the target's relational beliefs may moderate the effects of the agent's influence strategies on the target's health beliefs and health behavior (see the two dashed lines in Figure 1). Few of these paths have been tested empirically, so we build on the literature and logic in Section I to generate new predictions. The 
extent to which the target holds positive beliefs about the agent or their relationship should increase the likelihood that the target responds favorably to the agent's influence strategies. However, the manner in which these relational beliefs operate may differ depending on whether the influence strategy is designed to promote changes in beliefs or behavior.

Targets may be more responsive to agents' actions when their beliefs regarding their relationship are more positive. In fact, these relational beliefs may lead the target to construe changing their behavior as one way to maintain or increase feelings of closeness with the agent (e.g., the target believes that if they comply with the agent's request, it will show the agent that they care about the agent's needs and desires). Although these relational concerns may facilitate changes in behavior, the stability of the new health behavior may be contingent on the stability of these relational beliefs. If the target's relational beliefs fluctuate over time, so too might the target's behavior. For example, on days the target feels close to the agent, they may be responsive to encouragements to be physically active, whereas on days the target feels less close, they may remain sedentary. If so, observed changes in health behavior may reflect compliance rather than true conversion. Likewise, if the target perceives that there is inequity in the relationship such that they have been receiving more from the agent than they have been giving to the agent, the target may feel that they "owe" behavioral change to the agent to correct the imbalance. In such a case, the target may also be more likely to comply with the agent's influence attempt, but changes in behavior may not be stable, again reflecting compliance rather than conversion.

When an agent attempts to influence the target's health beliefs, the more the target perceives the agent as a trustworthy and credible source of information, the more successful the agent's influence attempts should be, a premise aligned with research on source credibility and 
attitude change (e.g., Petty \& Wegener, 1998). A target may have general trust in an agent as a component of relationship quality, and more specifically, the target may trust the agent's opinion when the agent has expertise in a relevant health domain. For example, if the agent is a nutritionist, the target may trust the agent's knowledge about diet, and thus be more likely to alter their health beliefs about eating. In close relationships, especially those with longer histories, targets are likely to have greater knowledge of agents' expertise about health behaviors, and thus, they may be better positioned to assess how credible agents are.

A target's relational beliefs should also affect how they respond to influence strategies designed to change their health behavior. The manner in which relational beliefs regulate these effects may depend on the features of the influence strategy used by the agent, the target's perceptions of the motivations underlying the agent's influence efforts, and how the target anticipates the agent will react to their health behavior change (or lack thereof).

The moderating effect of the target's relational beliefs could depend on the ty pe of influence strategy the agent uses (Tucker, 2002; Okun et al., 2007). If, for example, an agent relies on strategies that are autonomy-limiting (e.g., removing unhealthy snacks from the kitchen), more favorable relational beliefs may enable the target to tolerate these actions, at least initially, whereas unfavorable relational beliefs may exacerbate the target's adverse response to such strategies. If an agent relies on strategies that are autonomy-supportive (e.g., accepting, giving space, or showing patience with the target's choices), the target's relational beliefs may play a weaker moderating role because the agent is not infringing upon the target's free will.

The target may be more responsive to the agent's influence attempts if they attribute the agent's actions to concerns about the target's well-being as opposed to the agent's self-interested concerns (Lewis \& Butterfield, 2005; Tucker \& Mueller, 2000). For example, a target may 
respond more favorably if the agent acts out of care for the target's health, rather than out of care for the target's appearance. The target may be more likely to infer positive agent motivations the more the target perceives the relationship with the agent as highly interdependent.

A target's relational beliefs should not only shape their own behavioral response to the agent's attempts to influence their health behavior, but also shape their judgment of how the agent would react to their behavioral response. Targets may also evaluate whether the agent's predicted reaction would align with the target's expectations or goals for the future of the relationship. For example, if the target expects the agent will get angry in the face of noncompliance and the target is committed to maintaining the relationship, the target may change their behavior temporarily to avoid the negative reaction. This might be particularly true if the target is also uncertain about the agent's commitment to the relationship.

\section{Conclusion}

The DHIM identifies the ways in which agents can affect targets' health behavior via three primary routes: health behavior transmission, relational behaviors, and influence strategies. The model recognizes that these routes intersect at various places enroute to altering the target's health behavior. In this section, we have described how the target's relational beliefs are impacted by the agent's influence strategies and how the target's relational beliefs might moderate whether the agent's influence strategies are successful in eliciting behavior change in the target. This section highlights the importance of examining and assessing target's relational beliefs and how they affect and are affected by the agent's influence strategies. In the next section, we consider how targets' relational and health behavior responses feed back into the model and affect the agent's subsequent use of influence strategies. 


\section{Section III: The DHIM Over Time: How Targets' Behavioral Responses Shape Agents' Subsequent Behaviors}

The DHIM delineates how and when the agent's behavior - whether through the health behavior transmission route, the relational behaviors route, or the influence strategies routeshapes the target's health and relational behavior (see Table 1). This is merely one step in an ongoing series of interactions between the agent and the target that define a relationship (see Kelley et al., 1983); yet, existing theoretical models of interpersonal processes (Eastwick et al., 2019), including those addressing health behavior (Reed et al., 2013; Scholz, 2019), have not sufficiently specified how these processes unfold over time. There are several established feedback paths relevant to the DHIM that we have omitted to simplify the model ${ }^{2}$. Here we focus on the feedback loops that are most important for dyadic processes that may improve health behavior (see the light grey lines on the outside of Figure 1). Specifically, we discuss how the target's health behavior can inform the agent's beliefs about the target's health and how the target's health behavior can affect the agent's relational beliefs.

\section{Target's Health Behavior $\rightarrow$ Agent's Beliefs about Target's Health}

To the extent that the target's health behavior is observable (e.g., the agent observes the target exercising) or directly communicated to the agent (e.g., the target tells the agent that they exercised), the target's health behavior can feed back into the agent's beliefs about the target's health. There are two aspects of the target's health behavior that should be relevant for the agent's

2 Other feedback loops may include those from a person's health or behavior to their own health or relational beliefs. Additionally, targets' relational behaviors should shape agents' relational beliefs, and thus, their subsequent use of influence strategies over time. The target's health behavior could also shape the agent's health beliefs and behavior across time via the same mechanisms as in the health behavior transmission route. 
beliefs about the target's health: 1) whether or not the target engages in the health behavior desired by the agent, and 2) whether or not the target maintains the behavior change over time.

When targets make and sustain changes in their behavior, this should elicit more favorable beliefs about the target's health (e.g., lower risk appraisals or perceptions that the target has greater self-efficacy). Over time, these favorable changes may lead the agent to conclude they no longer need to rely on influence strategies to sustain the target's behavior. However, if the target is unable to sustain behavior changes, the agent may become more concerned about the target's health (e.g., develop higher risk appraisals). These beliefs may then lead the agent to change the type or intensity of the influence strategies they use, perhaps turning to more direct or more limiting influence strategies. One challenge that may emerge is that the agent and target may not agree about how much progress the target has made, with the target frequently being more optimistic in their assessment of progress. To the extent that the target believes they have made good progress, they may become increasingly frustrated by or resistant to the agent's repeated use of influence strategies, especially those that are direct or autonomy-limiting.

\section{Target's Health Behavior $\rightarrow$ Agent's Relational Beliefs}

Whether and how a target changes their health behavior is likely to affect their own health, but it may also affect how the agent views the target and their relationship. There are three ways in which the target's health behavior change (or lack thereof) might affect the agent's relational beliefs. First, if the target's health behavior change was the result of the agent's own health behavior practices (via the health behavior transmission route), the agent's relational 
Table 1. The Three Primary Routes by which Agents' Actions may Elicit Health Behavior Change in Targets.

\begin{tabular}{|c|c|c|c|}
\hline & $\begin{array}{c}\text { Health Behavior Transmission } \\
\text { (Route A) }\end{array}$ & $\begin{array}{c}\text { Relational Behaviors } \\
\text { (Route B) }\end{array}$ & $\begin{array}{c}\text { Influence Strategies } \\
\text { (Route C) }\end{array}$ \\
\hline $\begin{array}{l}\text { Direct effects on T's } \\
\text { health beliefs }\end{array}$ & $\begin{array}{l}\text {-A's health behavior can change T's } \\
\text { health beliefs }\end{array}$ & N/A & $\begin{array}{l}\text {-A's influence strategies can change T's } \\
\text { health beliefs }\end{array}$ \\
\hline $\begin{array}{l}\text { Direct effects on T's } \\
\text { health behavior }\end{array}$ & $\begin{array}{l}\text {-A's health behavior leads to } \\
\text { alterations to the physical } \\
\text { environment shared with the T } \\
\text {-A serves as a model for the T }\end{array}$ & N/A & $\begin{array}{l}\text {-Agent uses influence strategies to alter } \\
\text { the routines and physical environment } \\
\text { shared with the target }\end{array}$ \\
\hline $\begin{array}{l}\text { Effect on T's } \\
\text { relational beliefs and } \\
\text { behavior }\end{array}$ & N/A & $\begin{array}{l}\text {-T examines A's intentions and } \\
\text { whether A's actions were responsive } \\
\text {-T reacts positively or negatively }\end{array}$ & $\begin{array}{l}\text {-T examines A's intentions and whether } \\
\text { A's actions were responsive } \\
\text {-T may appreciate influence attempts or } \\
\text { resent them, leading to reactance }\end{array}$ \\
\hline $\begin{array}{l}\text { T's relational beliefs } \\
\text { as moderator on paths } \\
\text { to T's health beliefs } \\
\text { and behaviors }\end{array}$ & $\begin{array}{l}\text {-Determine how much of } \\
\text { environment is shared } \\
\text {-Determine effectiveness of modeling }\end{array}$ & N/A & $\begin{array}{l}\text {-Determine whether T changes beliefs } \\
\text {-Determine whether T complies } \\
\text { behaviorally }\end{array}$ \\
\hline
\end{tabular}

Note. $\mathrm{A}=$ Agent. $\mathrm{T}=$ Target. 
beliefs may shift. For example, if the target has changed their health behavior to be more similar to the agent's, the agent may perceive greater similarity between themselves and the target, which might increase closeness and relation ship satisfaction over time. Indeed, perceiving one's partner as being more similar to the self predicts both feeling more understood by the partner and higher relationship satisfaction (Murray et al., 2002). Additionally, becoming more similar to one's partner over time helps to maintain relationship satisfaction (Gonzaga et al., 2007). If, however, the target's health behavior does not change, the agent's perceptions of similarity are likely to remain unchanged.

Second, if the target alters their health behavior in response to the agent's relational behavior, the agent may not recognize that their actions caused the change, particularly because the agent's actions were done with the relationship in mind rather than the health behavior per se. The agent may more easily ascertain that their relational behavior created the change when the target already possessed the proper health beliefs but needed the agent's help to act on them. In such cases, agents may, over time, perceive greater interdependence between themselves and targets. In other cases, changes in targets' health behaviors may update agents' reciprocity beliefs. For instance, even though they acted out of care for the target, the agent may recognize that their provision of instrumental support (e.g., taking over the target's chores) allowed the target to turn their health beliefs into action (e.g., freed up time for the target to exercise). In such a case, the agent may expect that the target make sacrifices to support their goals in the future.

Finally, if the agent attempts to change the target's health behavior via intentional influence strategies, the agent is likely to monitor the target's health behavior to gauge the degree to which the influence attempt has been successful. In this case, the effect of the target's health behavior on the agent's relational beliefs should be especially strong. For example, if the target 
changes their health behavior, but the agent senses that the target is only complying and has not truly changed their health beliefs (conversion), the agent may infer that the target acted out of obligation or out of the desire to please the agent. Agents may then feel that they "owe" compliant targets in the future, thereby altering their relational beliefs about reciprocity. They could also feel grateful to targets and experience higher relationship satisfaction. Furthermore, if the target sustains their health behavior change, the agent may feel more positively about the target and their relationship. When the quality of the relationship is stren gthened, the relational behavior route may emerge as a key source of support for the target moving forward. However, if the target does not change their health behavior in response to the agent's influence, the agent may doubt the target's commitment to the relationship or feel that the target ignores their desires.

\section{Conclusion}

In sum, the changes in the target's health behavior (or lack of changes), as well as their successful (or unsuccessful) maintenance of the health behavior change over time should inform the agent's beliefs about the target's health. Additionally, whether and how a target changes their health behavior may also affect how the agent views the target and their relationship. Thus, the DHIM is ultimately a dyadic and dynamic model - both the agent and the target can influence and be influenced by each other over time. Additionally, the agent and the target can simultaneously influence each other's health and relational behaviors through the three routes.

\section{Section IV: Contextual Considerations When Testing the DHIM}

We have specified the intrapersonal and interpersonal processes implicated in dyadic health behavior influence in adult romantic relationships. Just as intrapersonal processes occur in an interpersonal context, the three central routes of the DHIM are also situated in a broader context. As researchers aim to test the three central routes of the DHIM (or paths within the three 
routes), there are several contextual factors to consider. In this section, we identify two examples of contextual factors that might affect the operation of the different routes specified in the DHIM: (1) the specific health behavior being examined, and (2) features of the external environment.

\section{Features of the Health Behavior}

Several facets of the health behavior may moderate the effect of agents' relational and health beliefs on targets' health beliefs and behavior. These include features that of ten emerge in discussions of health behavior change (e.g., frequency of the behavior, the severity of the underlying health issue) as well as features that emerge because of the dyadic context (e.g., whether or not both partners engage in the behavior, the visibility of the behavior). For example, whether or not both partners engage in a behavior, such as exercise, might affect how the agent tries to shape the target's behavior and, in turn, how the target responds to these efforts. If an agent believes it is important for both them selves and the target to exercise, agents may use influence strategies that involve intentional modeling or exercising together. Moreover, the target may perceive their behavior change more positively if they and the agent change their behavior together, especially if engaging in a new activity together or spending more time together enhances the quality of their relationship. Although some health behavior may be relevant to only the target (e.g., the target needs to take a medication more consistently), the extent to which the agent can integrate the behavior into the dynamics of their relationship may allow them to capitalize on opportunities for behavior change to reinforce the strength of their relationship.

In situations where the health behavior is less visible to the target, the health behavior transmission route is likely to be less effective. For example, the agent might regularly go to the gym during their lunch hour at work, but because the target does not witness the agent 
exercising, they cannot model the agent's behavior. The visibility of the behavior may also have implications for which influence strategies are most effective. Less visible behaviors may benefit from more direct strategies that ensure the target is mindful of the behavior. The visibility of the health behavior, however, ought to be less relevant to an agent's relational behaviors because those behaviors are driven more by relational beliefs than health beliefs in the DHIM.

Additionally, the frequency of the behavior might moderate how the agent approaches trying to shape the target's health beliefs and behavior. When a behavior occurs infrequently (e.g., a colonoscopy), the agent may be more willing to use influence strategies that require more effort. They may also be more willing to use strategies that are direct and autonomy-limiting because any adverse effect they might have on the relationship might be time-limited. For example, the agent may schedule an appointment for the target (or for both of them) to get a health checkup. But when a behavior occurs frequently (e.g., eating or exercise) and may require the repeated use of influence strategies, the agent is likely to be more attentive to how the target responds to the strategy, wary of causing negative relational outcomes. Behavioral frequency may also have implications for the health behavior transmission route, with its effectiveness contingent on a minimum level of frequency necessary for the target to take note of the behavior. Finally, behavioral frequency itself may not alter the effectiveness of the relational behaviors route, but when behavioral frequency is associated with the need for sustained effort (i.e., behaviors that are less likely to become habitual), the benefits afforded by the relational behaviors route may prove to be important.

Finally, the severity of the health issue associated with the behavior may also affect several pathways of the DHIM. If the agent is highly committed to the relationship and the health issue is severe (e.g., the target continues to smoke, despite being diagnosed with lung cancer), 
the agent may be more inclined to use direct and autonomy-limiting influence strategies, despite their potential to generate negative relational behaviors from the target. If the severity of the health issue requires rapid health behavior change, the agent may try to use an array of different strategies in the hope that one of them will work. Additionally, the severity of the health issue could alter the target's responses to the agent's use of influence strategies, whereby the target becomes more understanding of the agent's use of influence and reacts with more positive relational behaviors (Badr et al., 2015).

The severity of the health issue may not moderate the effectiveness of the relational and health behavior transmission routes, but it may impact their operation. For behaviors associated with more serious health problems, the agent may be more strongly motivated to modify their own behavior (e.g., being more active; eating a healthier diet), which in turn might increase the opportunity for health behavior transmission if the behavior is also relevant to the target. Similarly, the agent may be more willing to engage in relational behaviors that reduce the target's barriers to health behavior change if the health behavior change would prevent a severe health issue.

\section{Features of the Environment}

The DHIM situates health behavior change within the context of an ongoing romantic relationship, but it is also important to recognize that these behaviors and the relationship operate within a broader external environment and changes to the broader social or physical environment might have implications for the routes and paths specified in the DHIM.

With regard to the social environment, the formation of new relationships might change either the agent's or the target's health beliefs, such as their social norms. If, for example, their new friends drink alcohol more frequently, the agent and/or the target may believe drinking is 
more common than they previously did. These shifts in norms might also affect the agent's beliefs about the target's health (e.g., the agent may come to believe that it is acceptable for the target to drink alcohol frequently). Changes in social norms may also elicit changes in the agent's perceptions of what influence strategies are acceptable to use as well as the target's perceptions of the need to comply with them. For instance, gender roles pressure women, but not men, to manage the health of their partners and families (Williams et al., 2017). This, in turn, might lead to decreased use of influence strategies by men and increased use by women, or changes in the types of strategies used (e.g., using indirect and autonomy-supportive strategies rather than direct and autonomy-limiting ones).

Additionally, all relationships exist within a cultural context. Different cultures may have distinct norms regarding the prevalence and acceptability of certain actions and behaviors that are relevant to each of the DHIM's three routes. Some cultures, for example, tend to emphasize the importance of maintaining strong social connections and taking care of close others, especially family members (McCann et al., 2000; Ng et al., 2000; Pinquart \& Sörensen, 2005). Additionally, some cultures place different values on health and health behaviors (e.g., physical fitness; Chen et al., 2007; Kim et al., 2015). These distinct tendencies may affect the degree to which agents weigh health versus relational outcomes when deciding whether to and how to modify the target's health behavior.

Research has also shown that cultural context predicts support provision, such that European Americans report providing more emotion-focused support than Asian Americans (Chen et al., 2015). Thus, culture may affect the kinds of relational behaviors and influence strategies agents use. Other work has shown that people from some cultural backgrounds (e.g., Asians, Asian Americans) may benefit more from interpersonal support that is more indirect 
(i.e., the emotional comfort individuals can get from relationship partners without disclosing or discussing their problems) than direct (i.e., specifically asking for support from one's relational partners). This may be due to their concerns about the detrimental relational consequences of support-seeking (Kim et al., 2008). Similarly, cultural context may moderate the effectiveness of influence strategies, such that indirect strategies may be more effective than direct strategies in supporting health behavior changes. Thus, in particular cultural settings, or for individuals from particular cultural backgrounds, the influence and/or the relational route may exert a relatively stronger effect on targets' health behaviors.

External stressors, such as stressful life events and changes to the shared environment, can also affect the strength of the routes and paths in the DHIM. External stressors can affect the agent's behavior, such that greater stress may lead agents to be less likely to enact relational behaviors or influence strategies, which require time and energy. With regard to the target's behavior, external stress should weaken the paths from the agent's influence strategies to the target's health behavior. For instance, if a target is experiencing stressful life events, they may not feel capable or motivated to change their behavior, even if the agent uses influence strategies that are generally effective. Instead, the target may be more likely to successfully change their health behavior when the agent engages in negative-alleviating relational behaviors that would reduce the target's stress. Additionally, changes to the shared environment, or instability in the environment, may weaken aspects of the DHIM, such as the health behavior transmission route. For example, if the agent starts putting in more hours at work, there may be fewer opportunities for the target to observe their health behavior.

\section{Conclusion}


The DHIM operates within a broader context, such that the three primary routes and the paths within them, as well as the feedback loops, are affected by features of the health behavior, aspects of the social environment, the cultural context, and the physical and psychological shared environment. Although this is not an exhaustive list of contex tual factors relevant to the DHIM, this section provides a starting point for researchers to consider when seeking to apply and test routes of the DHIM.

\section{Conclusion}

There is an unquestionable need to conceptualize and understand the primary behavioral pathways through which relationship partners affect each other's health outcomes. The DHIM addresses this gap by articulating three routes through which one relationship partner (the agent) can affect the health beliefs and/or behavior of the other partner (the target) (see Figure 1 and Table 1). These routes involve processes associated with: (1) health-relevant behaviors enacted by the agent, (2) the relationship-based beliefs and behaviors of the agent and target that define their relationship, and (3) the type and amount of intentional influence strategies the agent uses to change the target's health behavior. To date, only a few of the paths in the DHIM have been explored empirically. Throughout the paper, we have enumerated several hypotheses and predictions that could be examined within the DHIM framework. To examine the model more fully and rigorously, investigators may identify relevant theories and principles in health psychology and relationship science that can be applied to and perhaps integrated with the DHIM to derive new, testable predictions. Although a central argument driving the development of the DHIM is that the health behavior transmission route, the relational behaviors route, and the influence strategies route need to be considered simultaneously, we recognize that it may prove difficult to test all three of the primary DHIM routes in a single research project. Therefore, we 
recommend that researchers begin by focusing on testing predictions from one or two paths within each route, while remaining mindful of the connections to the other central routes.

The DHIM advances our conceptualization and understanding of how and why influence operates as it does within close relationships in several important ways. For example, prior models of influence in relationships have focused on what agents do to change their partner's (the target's) health behavior but have ignored the agent's need to strike a balance between promoting or sustaining relational goals when attempting to change their partner's health behavior. Within close relationships, the specific influence tactics that agents use may often need to be geared to generate the most health behavior change while limiting potential costs or damage to their relationship. This may be why agents rarely enact the strongest possible influence tactics on their targets (partners). Moreover, the DHIM provides a novel explanation for why high-quality relationships tend to be associated with better health outcomes in partners via both the agent's positive relational behaviors as well as the health-promotion influence tactics they deploy on the target (their partner).

It is important to note that the roles of agent of influence and target of influence can and most likely do change across time within a relationship as the health-relevant issues and concerns associated with each partner change. At some point in time, agents of influence become targets and targets of influence become agents. This is likely to have important implications for when, how, and why agents do or do not enact certain influence tactics. If, for example, an agent knows that they will be the target of an influence attempt from their partner in the future, it may reduce the likelihood they will use highly limiting influence tactics, especially if they expect the partner to react negatively or they (agents) do not want such tactics used on them in future situations. 
This highlights another important element of the DHIM — the critical role that feedback paths assume in the model. For simplicity, we have presented a single snapshot of how the key variables and routes in the DHIM are likely to be interrelated. Nevertheless, the influence tactic that an agent enacts at a specific point in time along with the target's behavioral and emotional reaction ought to affect what both the agent does next and how the target subsequently responds. These feedback paths are capable of explaining when, how, and why agents either change or continue to enact the same influence tactics and when, how, and why targets react as they do to such tactics, potentially altering what agents, in turn, do later.

Moving forward, our hope is that future scholars will generate and examine additional novel hypotheses and predictions that can be derived from application of the DHIM. Doing so will not only expand our understanding of the sources that promote better health outcomes in relationship partners; it will also foster new theoretical and empirical connections between key constructs and psychological processes in both health and relationship science. 


\section{References}

Agnew, C. R., Van Lange, P. A., Rusbult, C. E., \& Langston, C. A. (1998). Cognitive interdependence: Commitment and the mental representation of close relationships. Journal of Personality and Social Psychology, 74(4), 939-954. https://doi.org/10.1037/0022-3514.74.4.939

American Psychological Association. (2014). Stress in America: Are teens adopting adults' stress habits? https://www.apa.org/news/press/releases/stress/2013/stress-report.pdf

Ashford, S., Edmunds, J., \& French, D. P. (2010). What is the best way to change selfefficacy to promote lifestyle and recreational physical activity? A systematic review with meta-analysis. British Journal of Health Psychology, 15(2), 265-288.

https://doi.org/10.1348/135910709X461752

Badr, H., Yeung, C., Lewis, M. A., Milbury, K., \& Redd, W. H. (2015). An observational study of social control, mood, and self-efficacy in couples during treatment for head and neck cancer. Psychology \& Health, 30(7), 783-802.

\section{https://doi.org/10.1080/08870446.2014.994633}

Balzarini, R. N., Muise, A., Zoppolat, G., Bartolomeo, A. D., Rodrigues, D. L., AlonsoFerres, M., Urganci, B., Debrot, A., Pichayayothin, N. B., Dharma, C., Chi, P., Karremans, J., Schoebi, D., \& Slatcher, R. B. (2020). Love in the time of COVID: Perceived partner responsiveness buffers people from lower relationship quality associated with COVID-related stressors. Manuscript submitted for publication. https://doi.org/10.31234/osf.io/e3fh4

Bandura, A. (1997). Self-Efficacy: The Exercise of Control. New York: Freeman. 
Bandura, A. (1977). Self-efficacy: Toward a unifying theory of behavioral change. Psychological Review, 84(2), 191-215. https://doi.org/10.1037/0033-295X.84.2.191

Bandura, A. (1971). Psychological modeling: Conflicting theory. Washington, DC: Library of Congress.

Bauer, U. E., Briss, P. A., Goodman, R. A., \& Bowman, B. A. (2014). Prevention of chronic disease in the 21 st century: Elimination of the leading preventable causes of premature death and disability in the USA. The Lancet, 384(9937), 45-52. https://doi.org/10.1016/S0140-6736(14)60648-6

Baumeister, R. F., \& Heatherton, T. F. (1996). Self-regulation failure: An overview. Psychological Inquiry, 7(1), 1-15. https://doi.org/10.1207/s15327965pli0701_1

Berkman, L. F., Glass, T., Brissette, I., \& Seeman, T. E. (2000). From social integration to health: Durkheim in the new millennium. Social Science \& Medicine, 51(6), 843-857. https://doi.org/10.1016/S0277-9536(00)00065-4

Berli, C., Bolger, N., Shrout, P. E., Stadler, G., \& Scholz, U. (2018a). Interpersonal processes of couples' daily support for goal pursuit: The example of physical activity. Personality and Social Psychology Bulletin, 44(3), 332-344. https://doi.org/10.1177/0146167217739264

Berli, C., Lüscher, J., Luszczynska, A., Schwarzer, R., \& Scholz, U. (2018b). Couples' daily self-regulation: The Health Action Process Approach at the dyadic level. PloS One, 13(10), e0205887. https://doi.org/10.1371/journal.pone.0205887

Biber, D. D., \& Ellis, R. (2019). The effect of self-compassion on the self-regulation of health behaviors: A systematic review. Journal of Health Psychology, 24(14), 2060-2071. https://doi.org/10.1177/1359105317713361 
Biehle, S. N., \& Mickelson, K. D. (2012). Provision and receipt of emotional spousal support: The impact of visibility on well-being. Couple and Family Psychology: Research and Practice, 1(3), 244-251. https://doi.org/10.1037/a0028480

Birditt, K. S., Cranford, J. A., Manalel, J. A., \& Antonucci, T. C. (2018). Drinking patterns among older couples: Longitudinal associations with negative marital quality. The Journals of Gerontology: Series B, 73(4), 655-665. https://doi.org/10.1093/geronb/gbw073

Bolger, N., Zuckerman, A., \& Kessler, R. C. (2000). Invisible support and adjustment to stress. Journal of Personality and Social Psychology, 79(6), 953-961. https://doi.org/10.1037/0022-3514.79.6.953

Bowlby, J. (1988). Developmental psychiatry comes of age. The American Journal of Psychiatry, 145(1), 1-10. https://doi.org/10.1176/ajp.145.1.1

Bowlby J (1969). Attachment and loss: Volume 1. London: Random House.

Brazeau, H., \& Lewis, N. A. (2020). Within-couple health behavior trajectories: The role of spousal support and strain. Health Psychology, 40, 125-134. https://doi.org/10.1037/hea0001050

Breines, J. G., \& Chen, S. (2012). Self-compassion increases self-improvement motivation. Personality and Social Psychology Bulletin, 38(9), 1133-1143. https://doi.org/10.1177/0146167212445599

Brock, R. L., \& Lawrence, E. (2009). Too much of a good thing: Underprovision versus overprovision of partner support. Journal of Family Psychology, 23(2), 181-192. https://doi.org/10.1037/a0015402 
Brown, E. G., Gallagher, S., \& Creaven, A. M. (2018). Loneliness and acute stress reactivity: A systematic review of psychophysiological studies. Psychophysiology, 55(5), e13031. https://doi.org/10.1111/psyp.13031

Burke, T. J., \& Segrin, C. (2017). Weight-related social control in couples: Associations with motives, constraints, and health behaviors. Communication Research, 44(3), 348-366. https://doi.org/10.1177/0093650215590606

Butterfield, R. M., \& Lewis, M. A. (2002). Health-related social influence: A social ecological perspective on tactic use. Journal of Social and Personal Relationships, 19(4), 505-526. https://doi.org/10.1177/0265407502019004050

Carlson, E. N. (2016). Meta-accuracy and relationship quality: Weighing the costs and benefits of knowing what people really think about you. Journal of Personality and Social Psychology, 111(2), 250-264. https://doi.org/10.1037/pspp0000107

Carr, R. M., Prestwich, A., Kwasnicka, D., Thøgersen-Ntoumani, C., Gucciardi, D. F., Quested, E., ... \& Ntoumanis, N. (2019). Dyadic interventions to promote physical activity and reduce sedentary behaviour: Systematic review and meta-analysis. Health Psychology Review, 13(1), 91-109. doi: 10.1080/17437199.2018.1532312

Chen, J. M., Kim, H. S., Sherman, D. K., \& Hashimoto, T. (2015). Cultural differences in support provision: The importance of relationship quality. Personality and Social Psychology Bulletin, 41(11), 1575-1589. https://doi.org/10.1177/0146167215602224

Chen, M. Y., James, K., \& Wang, E. K. (2007). Comparison of health-promoting behavior between Taiwanese and American adolescents: A cross-sectional questionnaire survey. International Journal of Nursing Studies, 44(1), 59-69.

https://doi.org/10.1016/j.ijnurstu.2005.11.015 
Christakis, N. A., \& Fowler, J. H. (2008). The collective dynamics of smoking in a large social network. New England Journal of Medicine, 358(21), 2249-2258. https://doi.org/10.1056/NEJMsa0706154

Chung, A., \& Rimal, R. N. (2016). Social norms: A review. Review of Communication Research, 4, 1-28. https://nbn-resolving.org/urn:nbn:de:0168-ssoar-457550

Cialdini, R. B., \& Goldstein, N. J. (2004). Social influence: Compliance and conformity. Annual Review of Psychology, 55, 591-621. https://doi.org/10.1146/annurev.psych.55.090902.142015

Cialdini, R. B., \& Griskevicius, V. (2010). Social influence. In R. F. Baumeister \& E. J. Finkel (Eds.), Advanced social psychology: The state of the science (pp. 385-417). New York: Oxford University Press.

Cialdini, R. B., \& Trost, M. R. (1998). Social influence: Social norms, conformity, and compliance. In D. T. Gilbert, S. T. Fiske, \& G. Lindzey (Eds.), The handbook of social psychology, vol. 2 (pp. 151-192). New York: McGraw-Hill.

Cohen, S. E., \& Syme, S. I. (1985). Social support and health. New York: Academic Press.

Collins, N. L., \& Feeney, B. C. (2000). A safe haven: An attachment theory perspective on support seeking and caregiving in intimate relationships. Journal of Personality and Social Psychology, 78(6), 1053-1073. https://doi.org/10.1037/0022-3514.78.6.1053

Conner, M., \& Norman, P. (2017). Health behaviour: Current issues and challenges. Psychology \& Health, 32(8), 895-906. https://doi.org/10.1080/08870446.2017.1336240 
Craddock, E., vanDellen, M. R., Novak, S. A., \& Ranby, K. W. (2015). Influence in relationships: A meta-analysis on health-related social control. Basic and Applied Social Psychology, 37(2), 118-130. https://doi.org/10.1080/01973533.2015.1011271

Cummings, J. R., \& Tomiyama, A. J. (2019). Food loves company: Risky eating with friends increases interpersonal closeness. Journal of Experimental Social Psychology, 81, 61 69. https://doi.org/10.1016/j.jesp.2018.07.006

Dailey, R. M. (2018). Strategies in context: How perceptions of romantic partner support for weight loss vary by the relational context. Health Communication, 34(10), 1095 1106. https://doi.org/10.1080/10410236.2018.1461584

Deci, E. L., \& Ryan, R. M. (2000). The" what" and" why" of goal pursuits: Human needs and the self-determination of behavior. Psychological Inquiry, 11(4), 227-268. https://doi.org/10.1207/S15327965PLI1104_01

Deci, E.L., \& Ryan, R.M. (1985). Intrinsic motivation and self-determination in human behavior. New York: Plenum.

Denissen, J. J., Penke, L., Schmitt, D. P., \& Van Aken, M. A. (2008). Self-esteem reactions to social interactions: Evidence for sociometer mechanisms across days, people, and nations. Journal of Personality and Social Psychology, 95(1), 181-196. http://dx.doi.org/10.1037/0022-3514.95.1.181

Derrick, J. L., Leonard, K. E., \& Homish, G. G. (2013). Perceived partner responsiveness predicts decreases in smoking during the first nine years of marriage. Nicotine \& Tobacco Research, 15(9), 1528-1536. https://doi.org/10.1093/ntr/ntt011 
DiMatteo, M. R. (2004). Social support and patient adherence to medical treatment: A metaanalysis. Health Psychology, 23(2), 207-811. https://doi.org/10.1037/0278$\underline{6133.23 .2 .207}$

Dinour, L., Leung, M. M., Tripicchio, G., Khan, S., \& Yeh, M. C. (2012). The association between marital transitions, body mass index, and weight: A review of the literature. Journal of Obesity, 2012, 1-16. https://doi.org/10.1155/2012/294974

Eastwick, P. W., Finkel, E. J., \& Simpson, J. A. (2019). Relationship trajectories: A metatheoretical framework and theoretical applications. Psychological Inquiry, 30(1), 1-28. https://doi.org/10.1080/1047840X.2019.1577072

El-Haddad, B., Dong, F., Kallail, K. J., Hines, R. B., \& Ablah, E. (2015). Association of marital status and colorectal cancer screening participation in the USA. Colorectal Disease, 17(5), O108-114. https://doi.org/10.1111/codi.12926

Epton, T., Harris, P. R., Kane, R., van Koningsbruggen, G. M., \& Sheeran, P. (2015). The impact of self-affirmation on health-behavior change: A meta-analysis. Health Psychology, 34(3), 187-196. https://doi.org/10.1037/hea0000116

Farrell, A. K., \& Stanton, S. C. E. (2019). Toward a mechanistic understanding of links between close relationships and physical health. Current Directions in Psychological Science, 28(5), 483-489. https://doi.org/10.1177/0963721419855657

Faseru B, Richter K. P., Scheuermann T. S., Park, E. W. (2018). Enhancing partner support to improve smoking cessation. Cochrane Database of Systematic Reviews, 8, CD002928. https://doi.org/10.1002/14651858.CD002928.pub4 
Feeney, B. C., \& Van Vleet, M. (2010). Growing through attachment: The interplay of attachment and exploration in adulthood. Journal of Social and Personal Relationships, 27(2), 226-234. https://doi.org/10.1177/0265407509360903

Feinstein, B. A., Latack, J. A., Bhatia, V., Davila, J., \& Eaton, N. R. (2016). Romantic relationship involvement as a minority stress buffer in gay/lesbian versus bisexual individuals. Journal of Gay \& Lesbian Mental Health, 20(3), 237-257. https://doi.org/10.1080/19359705.2016.1147401

Ferrer, R. A., Klein, W. M., Persoskie, A., Avishai-Yitshak, A., \& Sheeran, P. (2016). The tripartite model of risk perception (TRIRISK): Distinguishing deliberative, affective, and experiential components of perceived risk. Annals of Behavioral Medicine, 50(5), 653-663. https://doi.org/10.1007/s12160-016-9790-z

Finkel, E. J., Simpson, J. A., \& Eastwick, P. W. (2017). The psychology of close relationships: Fourteen core principles. Annual Review of Psychology, 68, 383-411. $\underline{\text { https://doi.org/10.1146/annurev-psych-010416-044038 }}$

Finney, J. W., \& Moos, R. H. (1984). Life stressors and problem drinking among older adults. In: Galenter M. et a. (Eds). Recent Developments in Alcoholism. Springer, Boston, MA. https://doi.org/10.1007/978-1-4684-4661-6_15

Fitzsimons, G. M., Finkel, E. J., \& vanDellen, M. R. (2015). Transactive goal dynamics. Psychological Review, 122(4), 648-673. https://doi.org/10.1037/a0039654

Floyd, K., Pauley, P. M., \& Hesse, C. (2010). State and trait affectionate communication buffer adults' stress reactions. Communication Monographs, 77(4), 618-636. https://doi.org/10.1080/03637751.2010.498792 
Foulstone, A. R., Kelly, A. B., \& Kifle, T. (2017). Partner influences on smoking cessation: A longitudinal study of couple relationships. Journal of Substance Use, 22(5), 501-506. https://doi.org/10.1080/14659891.2016.1255791

Gable, S. L., Reis, H. T., Impett, E. A., \& Asher, E. R. (2004). What do y ou do when things go right? The intrapersonal and interpersonal benefits of sharing positive events. Journal of Personality and Social Psychology, 87(2), 228-245. https://doi.org/10.1037/0022-3514.87.2.228

Garber, J., Robinson, N. S., \& Valentiner, D. (1997). The relation between parenting and adolescent depression: Self-worth as a mediator. Journal of Adolescent Research, 12(1), 12-33. https://doi.org/10.1177/0743554897121003

Ghassemi, M., Bernecker, K., \& Brandstätter, V. (2020). “Take care, honey!”: People are more anxious about their significant others' risk behavior than about their own. Journal of Experimental Social Psychology, 86, 103879. https://doi.org/10.1016/j.jesp.2019.103879

Girme, Y. U., Overall, N. C., \& Simpson, J. A. (2013). When visibility matters: Short-term versus long-term costs and benefits of visible and invisible support. Personality and Social Psychology Bulletin, 39(11), 1441-1454. https://doi.org/10.1177/0146167213497802

Golan, R., Schwarzfuchs, D., Stampfer, M. J., \& Shai, I. (2010). Halo effect of a weight-loss trial on spouses: The DIRECT-Spouse study. Public Health Nutrition, 13(4), 544-549. https://doi.org/10.1017/S1368980009991273 
Gonzaga, G. C., Campos, B., \& Bradbury, T. (2007). Similarity, convergence, and relationship satisfaction in dating and married couples. Journal of Personality and Social Psychology, 93(1), 34-48. https://doi.org/10.1037/0022-3514.93.1.34

Gorin, A. A., Lenz, E. M., Cornelius, T., Huedo-Medina, T., Wojtanowski, A. C., \& Foster, G. D. (2018). Randomized controlled trial examining the ripple effect of a nationally available weight management program on untreated spouses. Obesity, 26, 499-504. https://doi.org/10.1002/oby.22098

Gorin, A. A., Powers, T. A., Gettens, K., Cornelius, T., Koestner, R., Mobley, A. R., Pescatello, L. S., \& Huedo-Medina, T. B. (2020). A randomized controlled trial of a theory-based weight-loss program for couples. Health Psychology, 39(2), 137-146. https://doi.org/10.1037/hea0000808

Gorin, A. A., Wing, R. R., Fava, J. L., Jakicic, J. M., Jeffery, R., West, D. S., ... \& DiLillo, V. G. (2008). Weight loss treatment influences untreated spouses and the home environment: Evidence of a ripple effect. International Journal of Obesity, 32(11), 1678-1684. https://doi.org/10.1038/ijo.2008.150

Gouin, J. P., Glaser, R., Loving, T. J., Malarkey, W. B., Stowell, J., Houts, C., \& KiecoltGlaser, J. K. (2009). Attachment avoidance predicts inflammatory responses to marital conflict. Brain, Behavior, and Immunity, 23(7), 898-904. https://doi.org/10.1016/j.bbi.2008.09.016

Grunberg, N. E., \& Straub, R. O. (1992). The role of gender and taste class in the effects of stress on eating. Health Psychology, 11(2),97-100. https://doi.org/10.1037/0278$\underline{6133.11 .2 .97}$ 
Guadagno, R. E., \& Cialdini, R. B. (2010). Preference for consistency and social influence: A review of current research findings. Social Influence, 5(3), 152-163.

\section{https://doi.org/10.1080/15534510903332378}

Hasford, J., Kidwell, B., \& Lopez-Kidwell, V. (2018). Happy wife, happy life: Food choices in romantic relationships. Journal of Consumer Research, 44(6), 1238-1256. https://doi.org/10.1093/jcr/ucx093

Heaney, C. A., \& Israel, B. A. (2008). Social networks and social support. In (Eds.) Glanz, K., Rimber, B. K., \& Viswanath, K. Health behavior and health education: Theory, research, and practice, $4^{\text {th }}$ edition. John Wiley \& Sons. (pp 189-210).

Heinz, A. J., Wu, J., Witkiewitz, K., Epstein, D. H., \& Preston, K. L. (2009). Marriage and relationship closeness as predictors of cocaine and heroin use. Addictive Behaviors, 34, 258-263. doi:10.1037/0033-2909.118.1.3

Hira, S. N., \& Overall, N. C. (2011). Improving intimate relationships: Targeting the partner versus changing the self. Journal of Social and Personal Relationships, 28(5), 610633. https://doi.org/10.1177/0265407510388586

Hochbaum, G., Rosenstock, I., \& Kegels, S. (1952). Health belief model. Washington, EC: U.S. Public Health Service.

Hohl, D. H., Knoll, N., Wiedemann, A., Keller, J., Scholz, U., Schrader, M., \& Burkert, S. (2016). Enabling or cultivating? The role of prostate cancer patients' received partner support and self-efficacy in the maintenance of pelvic floor exercise following tumor surgery. Annals of Behavioral Medicine, 50(2), 247-258.

https://doi.org/10.1007/s12160-015-9748-6 
Hohl, D. H., Lüscher, J., Keller, J., Heuse, S., Scholz, U., Luszczynska, A., \& Knoll, N. (2018). Inter-relations among negative social control, self-efficacy, and physical activity in healthy couples. British Journal of Health Psychology, 23(3), 580-596. https://doi.org/10.1111/bjhp.12305

Holt-Lunstad, J. (2018). Relationships and physical health. In A. L. Vangelisti \& D. Perlman (Eds.), The Cambridge handbook of personal relationships (pp. 449-463). New York: Cambridge University Press. https://doi.org/10.1017/9781316417867.035

Holt-Lunstad, J., Smith, T. B., \& Layton, J. B. (2010). Social relationships and mortality risk: A meta-analytic review. PLoS Medicine, 7(7), e1000316. https://doi.org/10.1371/journal.pmed.1000316

Homish, G. G., \& Leonard, K. E. (2008). Spousal influence on general health behaviors in a community sample. American Journal of Health Behavior, 32(6), 754-763.

DOI: https://doi.org/10.5993/AJHB.32.6.19

Hostinar, C. E. (2015). Recent developments in the study of social relationships, stress responses, and physical health. Current Opinion in Psychology, 5, 90-95. https://doi.org/10.1016/j.copsyc.2015.05.004

House, G.S. (1981) Work stress and social support. New York: Addison-Wesley.

House, J. S., Landis, K. R., \& Umberson, D. (1988). Social relationships and health. Science, 241(4865), 540-545. DOI: 10.1126/science.3399889

Howland, M., Farrell, A. K., Simpson, J. A., Rothman, A. J., Burns, R. J., Fillo, J., \& Wlaschin, J. (2016). Relational effects on physical activity: A dyadic approach to the theory of planned behavior. Health Psychology, 35(7), 733-741. https://doi.org/10.1037/hea0000334 
Huelsnitz, C. O., Rothman, A. J., \& Simpson, J. A. (Revise \& Resubmit at Annals of Behavioral Medicine). Effects of social control on eating and relational behaviors in romantic relationships.

Huelsnitz, C. O., Simpson, J. A., Rothman, A. J., \& Englund, M. M. (2019). The interplay between relationship effectiveness, life stress, and sleep: A prospective study. Personal Relationships, 26(1), 73-92. https://doi.org/10.1111/pere.12266

Huelsnitz, C. O., Turbitt, E., Taber, J. M., Lewis, K. L., Biesecker, L. G., Biesecker, B. B., \& Klein, W. M. (2021). Dyadic concordance and associations of beliefs with intentions to learn carrier results from genomic sequencing. Journal of Behavioral Medicine, 1-7. https://doi.org/10.1007/s10865-021-00222-0

Huntsinger, E. T., \& Luecken, L. J. (2004). Attachment relationships and health behavior: The mediational role of self-esteem. Psychology \& Health, 19(4), 515-526. https://doi.org/10.1080/0887044042000196728

Hughes, M., \& Gove, W. R. (1981). Living alone, social integration, and mental health. American Journal of Sociology, 87(1), 48-74. https://doi.org/10.1086/227419

Jackson, S. E., Steptoe, A., \& Wardle, J. (2015). The influence of partner's behavior on health behavior change: The English Longitudinal Study of Ageing. JAMA Internal Medicine, 175(3), 385-392. https://doi.org/10.1001/jamainternmed.2014.7554

Janssen, M., Heerkens, Y., Kuijer, W., Van Der Heijden, B., \& Engels, J. (2018). Effects of Mindfulness-Based Stress Reduction on employees' mental health: A systematic review. PloS one, 13(1), e0191332.https://doi.org/10.1371/journal.pone.0191332 
Jayamaha, S. D., Antonellis, C., \& Overall, N. C. (2016). Attachment insecurity and inducing guilt to produce desired change in romantic partners. Personal Relationships, 23(2), 311-338. https://doi.org/10.1111/pere.12128

Jiang, X., Wang, J., Lu, Y., Jiang, H., \& Li, M. (2019). Self-efficacy-focused education in persons with diabetes: A systematic review and meta-analysis. Psychology Research and Behavior Management, 12, 67-79. https://doi.org/10.2147/PRBM.S192571

Karan, A., Rosenthal, R., \& Robbins, M. L. (2019). Meta-analytic evidence that we-talk predicts relationship and personal functioning in romantic couples. Journal of Social and Personal Relationships, 36(9), 2624-2651. https://doi.org/10.1177/0265407518795336

Karney, B. R., \& Bradbury, T. N. (1995). The longitudinal course of marital quality and stability: A review of theory, methods, and research. Psychological Bulletin, 118(1), 3-34. http://doi.org/10.1037/0033-2909.118.1.3

Karney, B. R., Hops, H., Redding, C. A., Reis, H. T., Rothman, A. J., \& Simpson, J. A. (2010). A framework for incorporating dyads in models of HIV-prevention. AIDS and Behavior, 14(2), 189-203. https://doi.org/10.1007/s10461-010-9802-0

Karremans, J. C., Schellekens, M. P., \& Kappen, G. (2017). Bridging the sciences of mindfulness and romantic relationships: A theoretical model and research agenda. Personality and Social Psychology Review, 21(1), 29-49. https://doi.org/10.1177/1088868315615450

Kehayes, I. L. L., Mackinnon, S. P., Sherry, S. B., Leonard, K. E., \& Stewart, S. H. (2017). Similarity in romantic couples' drinking motivations and drinking behaviors. Substance Abuse, 38(4), 488-492.https://doi.org/10.1080/08897077.2017.1355869 
Kelley, H. H., Berscheid, E., Christensen, A., Harvey, J. H., Huston, T. L., Levinger, G., McClintock, E., Peplau, L. A., \& Peterson, D. R. (1983). Close Relationships. San Francisco: Freeman.

Kelley, H. H., \& Thibaut, J. W. (1978). Interpersonal relations: A theory of interdependence. New York: John Wiley \& Sons.

Kenny, D. A., Kashy, D. A., \& Cook, W. L. (2006). Dyadic data analysis. New York: Guilford.

Kiecolt-Glaser, J. K., Gouin, J. P., \& Hantsoo, L. (2010). Close relationships, inflammation, and health. Neuroscience \& Biobehavioral Reviews, 35(1), 33-38. https://doi.org/10.1016/j.neubiorev.2009.09.003

Kiecolt-Glaser, J. K., Loving, T. J., Stowell, J. R., Malarkey, W. B., Lemeshow, S., Dickinson, S. L., \& Glaser, R. (2005). Hostile marital interactions, proinflammatory cytokine production, and wound healing. Archives of General Psychiatry, 62(12), 1377-1384. https://doi.org/10.1001/archpsyc.62.12.1377

Kiecolt-Glaser, J. K., McGuire, L., Robles, T. F., \& Glaser, R. (2002). Emotions, morbidity, and mortality: New perspectives from psychoneuroimmunology. Annual Review of Psychology, 53(1), 83-107. https://doi.org/10.1146/annurev.psych.53.100901.135217

Kiecolt-Glaser, J. K., \& Newton, T. L. (2001). Marriage and health: His and hers. Psychological Bulletin, 127(4), 472-503. https://doi.org/10.I037//0033-2909.127.4.472

Kim, H. J., Choi-Kwon, S., Kim, H., Park, Y. H., \& Koh, C. K. (2015). Health-promoting lifestyle behaviors and psychological status among Arabs and Koreans in the United Arab Emirates. Research in Nursing \& Health, 38(2), 133-141.

https://doi.org/10.1002/nur.21644 
Kim, H. S., Sherman, D. K., \& Taylor, S. E. (2008). Culture and social support. American Psychologist, 63(6), 518-526. https://doi.org/10.1037/0003-066X

Klein, W. M., \& Ferrer, R. A. (2018). On being more amenable to threatening risk messages concerning close others (vis-a-vis the self). Personality and Social Psychology Bulletin, 44(10), 1411-1423. https://doi.org/10.1177/0146167218769064

Klein, S. R., Renshaw, K. D., \& Curby, T. W. (2016). Emotion regulation and perceptions of hostile and constructive criticism in romantic relationships. Behavior Therapy, 47(2), 143-154. https://doi.org/10.1016/j.beth.2015.10.007

Knee, C. R., Hadden, B. W., Porter, B., \& Rodriguez, L. M. (2013). Self-determination theory and romantic relationship processes. Personality and Social Psychology Review, 17(4), 307-324. https://doi.org/10.1177/1088868313498000

Knee, C. R., Lonsbary, C., Canevello, A., \& Patrick, H. (2005). Self-determination and conflict in romantic relationships. Journal of Personality and Social Psychology, 89, 997-1009. https://doi.org/10.1037/0022-3514.89.6.997

Koestner, R., Powers, T. A., Carbonneau, N., Milyavskaya, M., \& Chua, S. N. (2012). Distinguishing autonomous and directive forms of goal support: Their effects on goal progress, relationship quality, and subjective well-being. Personality and Social Psychology Bulletin, 38(12), 1609-1620. https://doi.org/10.1177/0146167212457075

Kunce, L. J., \& Shaver, P. R. (1994). An attachment-theoretical approach to caregiving in romantic relationships. Presented at the 6th International Conference on Personal Relationships, Orono, ME. 
La Guardia, J. G., \& Patrick, H. (2008). Self-determination theory as a fundamental theory of close relationships. Canadian Psychology/Psychologie canadienne, 49(3), 201-209. https://doi.org/10.1037/a0012760

Lathren, C. R., Rao, S. S., Park, J., \& Bluth, K. (2021). Self-compassion and current close interpersonal relationships: A scoping literature review. Mindfulness, 12, 1078-1093. https://doi.org/10.1007/s12671-020-01566-5

Lazarus, R. S., \& Folkman, S. (1984). Stress, appraisal, and coping. New York: Springer.

Leary, M. R., Tambor, E. S., Terdal, S. K., \& Downs, D. L. (1995). Self-esteem as an interpersonal monitor: The sociometer hypothesis. Journal of Personality and Social Psychology, 68(3), 518-530. https://doi.org/10.1037/0022-3514.68.3.518

Leigh-Hunt, N., Bagguley, D., Bash, K., Turner, V., Turnbull, S., Valtorta, N., \& Caan, W. (2017). An overview of systematic reviews on the public health consequences of social isolation and loneliness. Public Health, 152, 157-171. https://doi.org/10.1016/j.puhe.2017.07.035

Lewis, M. A., \& Butterfield, R. M. (2007). Social control in marital relationships: Effect of one's partner on health behaviors. Journal of Applied Social Psychology, 37(2), 298319. https://doi.org/10/1111/j.0012-9029.2007.00161.x

Lewis, M. A., \& Butterfield, R. M. (2005). Antecedents and reactions to health-related social control. Personality and Social Psychology Bulletin, 31(3), 416-427. https://doi.org/10.1177/0146167204271600

Lewis, M. A., Butterfield, R. M., Darbes, L. A., \& Johnston-Brooks, C. (2004). The conceptualization and assessment of health-related social control. Journal of Social 
and Personal Relationships, 21(5), 669-687. https://doi.org/10.1177/0265407504045893

Lewis, M. A., McBride, C. M., Pollak, K. I., Puleo, E., Butterfield, R. M., \& Emmons, K. M. (2006). Understanding health behavior change among couples: An interdependence and communal coping approach. Social Science \& Medicine, 62(6), 1369-1380. https://doi.org/10.1016/j.socscimed.2005.08.006

Lewis, M. A., \& Rook, K. S. (1999). Social control in personal relationships: Impact on health behaviors and psychological distress. Health Psychology, 18(1), 63-71. https://doi.org/10.1037/0278-6133.18.1.63

Li, K. K., Cardinal, B. J., \& Acock, A. C. (2013). Concordance of physical activity trajectories among middle-aged and older married couples: Impact of diseases and functional difficulties. Journals of Gerontology Series B: Psychological Sciences and Social Sciences, 68(5), 794-806. https://doi.org/10.1093/geronb/gbt068

Loving, T. J., \& Slatcher, R. B. (2013). Romantic relationships and health. In J. A. Simpson \& L. Campbell (Eds.), The Oxford handbook of close relationships (p. 617-637). New York: Oxford University Press.

Lüscher, J., Hohl, D. H., Knoll, N., \& Scholz, U. (2019). Invisible social support and invisible social control in dual-smoker couple's everyday life: A dyadic perspective. Annals of Behavioral Medicine, 53(6), 527-540. https://doi.org/10.1093/abm/kay062

Lüscher, J., Ochsner, S., Knoll, N., Stadler, G., Hornung, R., \& Scholz, U. (2014). Examining gender differences in received, provided, and invisible social control: An application of the dual-effects model. Anxiety, Stress and Coping, 27(6), 678-694.

https://doi.org/10.1080/10615806.2014.892585 
Lüscher, J., \& Scholz, U. (2017). Does social support predict smoking abstinence in dualsmoker couples? Evidence from a dyadic approach. Anxiety, Stress, \& Coping, 30(3), 273-281. https://doi.org/10.1080/10615806.2016.1270448

Lüscher, J., Stadler, G., Ochsner, S., Rackow, P., Knoll, N., Hornung, R., \& Scholz, U. (2015). Daily negative affect and smoking after a self -set quit attempt: The role of dyadic invisible social support in a daily diary study. British Journal of Health Psychology, 20(4), 708-723. https://doi.org/10.1111/bjhp.12135

Lüscher, J., Stadler, G., \& Scholz, U. (2017). A daily diary study of joint quit attempts by dual-smoker couples: The role of received and provided social support. Nicotine and Tobacco Research, 20(1), 100-107.https://doi.org/10.1093/ntr/ntx079

Maisel, N. C., \& Gable, S. L. (2009). The paradox of received social support: The importance of responsiveness. Psychological Science, 20(8), 928-932. https://doi.org/10.1111/j.1467-9280.2009.02388.x

Marigold, D. C., Holmes, J. G., \& Ross, M. (2007). More than words: Reframing compliments from romantic partners fosters security in low self-esteem individuals. Journal of Personality and Social Psychology, 92(2), 232-248. https://doi.org/10.1037/0022-3514.92.2.232

Martire, L. M., \& Helgeson, V. S. (2017). Close relationships and the management of chronic illness: Associations and interventions. American Psychologist, 72(6), 601-612. https://doi.org/10.1037/amp0000066

Martire, L. M., Schulz, R., Helgeson, V. S., Small, B. J., \& Saghafi, E. M. (2010). Review and meta-analysis of couple-oriented interventions for chronic illness. Annals of Behavioral Medicine, 40(3), 325-342. https://doi.org/10.1007/s12160-010-9216-2 
McLeod, S., Berry, K., Hodgson, C., \& Wearden, A. (2020). Attachment and social support in romantic dyads: A systematic review. Journal of Clinical Psychology, 76(1), 59-101. https://doi.org/10.1002/jclp.22868

McCann, J. J., Hebert, L. E., Beckett, L. A., Morris, M. C., Scherr, P. A., \& Evans, D. A. (2000). Comparison of informal caregiving by black and white older adults in a community population. Journal of the American Geriatrics Society, 48(12), 16121617. https://doi.org/10.1111/j.1532-5415.2000.tb03872.x

McGinnis, J. M., Williams-Russo, P., \& Knickman, J. R. (2002). The case for more active policy attention to health promotion. Health Affairs, 21, 78-93. https://doi.org/10.1377/hlthaff.21.2.78

Meltzer, A. L., Novak, S. A., McNulty, J. K., Butler, E. A., \& Karney, B. R. (2013). Marital satisfaction predicts weight gain in early marriage. Health Psychology, 32(7), 824827. https://doi.org/10.1037/a0031593

Meyer, D. D., Jones, M., Rorer, A., \& Maxwell, K. (2015). Examining the associations among attachment, affective state, and romantic relationship quality. The Family Journal, 23(1), 18-25. https://doi.org/10.1177/1066480714547698

Meyler, D., Stimpson, J. P., \& Peek, M. K. (2007). Health concordance within couples: A systematic review. Social Science \& Medicine, 64(11), 2297-2310. https://doi.org/10.1016/j.socscimed.2007.02.007

Mikulincer, M., \& Florian, V. (1997). Are emotional and instrumental supportive interactions beneficial in times of stress? The impact of attachment style. Anxiety, Stress, and Coping, 10(2), 109-127. https://doi.org/10.1080/10615809708249297 
Mikulincer, M., \& Shaver, P. R. (2016). Attachment in adulthood: Structure, dynamics, and change (2 $2^{\text {nd }}$ ed.). New York: Guilford.

Moos, R. H., \& Schaefer, J. A. (1993). Coping resources and processes: Current concepts and measures. In L. Goldberger \& S. Breznitz (Eds.), Handbook of stress: Theoretical and clinical aspects (pp. 234-257). New York: Free Press.

Mund, M., Finn, C., Hagemeyer, B., Zimmermann, J., \& Neyer, F. J. (2015). The dynamics of self-esteem in partner relationships. European Journal of Personality, 29(2), 235-249. https://doi.org/10.1002/per.1984

Murray, S. L., Holmes, J. G., Bellavia, G., Griffin, D. W., \& Dolderman, D. (2002). Kindred spirits? The benefits of egocentrism in close relationships. Journal of Personality and Social Psychology, 82(4), 563-581. https://doi.org/10.1037/0022-3514.82.4.563

Murray, S. L., Holmes, J. G., \& Collins, N. L. (2006). Optimizing assurance: The risk regulation system in relationships. Psychological Bulletin, 132(5), 641-666. https://doi.org/10.1037/0033-2909.132.5.641

Murray, S. L., Holmes, J. G., \& Griffin, D. W. (2000). Self-esteem and the quest for felt security: How perceived regard regulates attachment processes. Journal of Personality and Social Psychology, 78(3), 478-498. https://doi.org/10.1037/0022-3514.78.3.478

Murray, S. L., Holmes, J. G., \& Griffin, D. W. (1996). The benefits of positive illu sions: Idealization and the construction of satisfaction in close relationships. Journal of Personality and Social Psychology, 70(1), 79-98. https://doi.org/10.1037/0022$\underline{3514.70 .1 .79}$

Mushquash, A. R., Stewart, S. H., Sherry, S. B., Mackinnon, S. P., Antony, M. M., \& Sherry, D. L. (2013). Heavy episodic drinking among dating partners: A longitudinal actor- 
partner interdependence model. Psychology of Addictive Behaviors, 27(1), 178-183. https://doi.org/10.1037/a0026653

Myers Virtue, S., Manne, S. L., Kashy, D., Heckman, C. J., Zaider, T., Kissane, D. W., ... \& Olekson, G. (2015). Correspondence of physical activity and fruit/vegetable consumption among prostate cancer survivors and their spouses. European Journal of Cancer Care, 24(6), 827-839. https://doi.org/10.1111/ecc.12316

Neff, K. D. (2011). Self-compassion, self-esteem, and well-being. Social and Personality Psychology Compass, 5(1), 1-12. https://doi.org/10.1111/j.1751-9004.2010.00330.x

Neff, K. (2003). Self-compassion: An alternative conceptualization of a healthy attitude toward oneself. Self and Identity, 2(2), 85-101. https://doi.org/10.1080/15298860309032

Neff, K. D., \& Germer, C. K. (2013). A pilot study and randomized controlled trial of the mindful self-compassion program. Journal of Clinical Psychology, 69(1), 28-44. https://doi.org/10.1002/jclp.21923

Neff, L. A., \& Karney, B. R. (2004). How does context affect intimate relationships? Linking external stress and cognitive processes within marriage. Personality and Social Psychology Bulletin, 30(2), 134-148. https://doi.org/10.1177/0146167203255984

Neff, K. D., \& Vonk, R. (2009). Self-compassion versus global self-esteem: Two different ways of relating to oneself. Journal of Personality, 77(1), 23-50. https://doi.org/10.1111/j.1467-6494.2008.00537.x

Newsom, J. T., Shaw, B. A., August, K. J., \& Strath, S. J. (2018). Physical activity-related social control and social support in older adults: Cognitive and emotional pathways to 
physical activity. Journal of Health Psychology, 23(11), 1389-1404. https://doi.org/10.1177/1359105316656768

Ng, D. M., \& Jeffery, R. W. (2003). Relationships between perceived stress and health behaviors in a sample of working adults. Health Psychology, 22(6), 638-642. https://doi.org/10.1037/0278-6133.22.6.638

Ng, S. H., Loong, C. S. F., Liu, J. H., \& Weatherall, A. (2000). Will the young support the old? An individual- and family-level study of filial obligations in two New Zealand cultures. Asian Journal of Social Psychology, 3(2), 163-182. https://doi.org/10.1111/1467-839X.00061

Novak, J. R. (2019). Initial development of a new scale for examining couples' beliefs about their role in their partner's health: The Relationship Health Belief Scale. Families, Systems, \& Health, 37(3), 224-234.https://doi.org/10.1037/fsh0000434

Novak, S. A., \& Webster, G. D. (2011). Spousal social control during a weight loss attempt: A daily diary study. Personal Relationships, 18(2), 224-241. https://doi.org/10.1111/j.1475-6811.2011.01358.x

Ochsner, S., Luszczynska, A., Stadler, G., Knoll, N., Hornung, R., \& Scholz, U. (2014). The interplay of received social support and self-regulatory factors in smoking cessation. Psychology \& Health, 29(1), 16-31. https://doi.org/10.1080/08870446.2013.818674

Ogedegbe, G. O., Boutin-Foster, C., Wells, M. T., Allegrante, J. P., Isen, A. M., Jobe, J. B., \& Charlson, M. E. (2012). A randomized controlled trial of positive-affect intervention and medication adherence in hypertensive African Americans. Archives of Internal Medicine, 172(4), 322-326. https://doi.org/10.1001/archinternmed.2011.1307 
Okun, M. A., Huff, B. P., August, K. J., \& Rook, K. S. (2007). Testing hypotheses distilled from four models of the effects of health-related social control. Basic and Applied Social Psychology, 29(2), 185-193. https://doi.org/10.1080/01973530701332245

Oriña, M. M., Simpson, J. A., Ickes, W., Asada, K. J. K., \& Fitzpatrick, S. (2008). Making it (inter-)personal: Self- and partner-moderated influence during marital conflict discussions. Social Influence, 3(1), 34-66. doi:10.1080/15534510701774193

Overall, N. C. (2020). Behavioral variability reduces the harmful longitudinal effects of partners' negative-direct behavior on relationship problems. Journal of Personality and Social Psychology, 119(5), 1057-1085. https://doi.org/10.1037/pspi0000231

Overall, N. C., \& Fletcher, G. J. (2010). Perceiving regulation from intimate partners: Reflected appraisal and self-regulation processes in close relationships. Personal Relationships, 17(3), 433-456. https://doi.org/10.1111/j.1475-6811.2010.01286.x

Overall, N. C., Fletcher, G. J., \& Simpson, J. A. (2010). Helping each other grow: Romantic partner support, self-improvement, and relationship quality. Personality and Social Psychology Bulletin, 36(11), 1496-1513. https://doi.org/10.1177/0146167210383045

Overall, N. C., Fletcher, G. J., \& Simpson, J. A. (2006). Regulation processes in intimate relationships: The role of ideal standards. Journal of Personality and Social Psychology, 91(4), 662-685.htpps://doi.org/10.1037/0022-3514.91.4.662

Overall, N. C., Fletcher, G. J., Simpson, J. A., \& Sibley, C. G. (2009). Regulating partners in intimate relationships: The costs and benefits of different communication strategies. Journal of Personality and Social Psychology, 96(3), 620-639. https://doi.org/10.1037/a0012961 
Overall, N. C., \& McNulty, J. K. (2017). What type of communication during conflict is beneficial for intimate relationships? Current Opinion in Psychology, 13, 1-5. https://doi.org/10.1016/j.copsyc.2016.03.002

Overall, N. C., Simpson, J. A., \& Struthers, H. (2013). Buffering attachment-related avoidance: Softening emotional and behavioral defenses during conflict discussions. Journal of Personality and Social Psychology, 104(5), 854-871. https://doi.org/10.1037/a0031798

Pachucki, M. A., Jacques, P. F., \& Christakis, N. A. (2011). Social network concordance in food choice among spouses, friends, and siblings. American Journal of Public Health, 101(11), 2170-2177. https://doi.org/10.2105/AJPH.2011.300282

Patrick, H., Knee, C. R., Canevello, A., \& Lonsbary, C. (2007). The role of need fulfillment in relationship functioning and well-being: A self-determination theory perspective. Journal of Personality and Social Psychology, 92, 434-457. https://doi.org/10.1037/0022-3514.92.3.434

Payne, N., Jones, F., \& Harris, P. R. (2005). The impact of job strain on the predictive validity of the theory of planned behaviour: An investigation of exercise and healthy eating. British Journal of Health Psychology, 10(1), 115-131.

\section{https://doi.org/10.1348/135910704X14636}

Petty, R. E., \& Wegener, D. T. (1998). Attitude change: Multiple roles for persuasion variables. In D. T. Gilbert, S. T. Fiske, \& G. Lindzey (Eds.), The handbook of social psychology (pp. 323-390). Retrieved from https://psycnet.apa.org/record/1998-07091$\underline{008}$ 
Pietromonaco, P. R., \& Collins, N. L. (2017). Interpersonal mechanisms linking close relationships to health. American Psychologist, 72(6), 531-542. https://doi.org/10.1037/amp0000129

Pietromonaco, P. R., Uchino, B., \& Dunkel Schetter, C. (2013). Close relationship processes and health: Implications of attachment theory for health and disease. Health Psychology, 32(5), 499-513.https://doi.org/10.1037/a0029349

Pinquart, M., \& Sörensen, S. (2003). Associations of stressors and uplifts of caregiving with caregiver burden and depressive mood: A meta-analysis. The Journals of Gerontology Series B: Psychological Sciences and Social Sciences, 58(2), P112-P128. https://doi.org/10.1093/geront/45.1.90

Prestwich, A., Kellar, I., Parker, R., MacRae, S., Learmonth, M., Sykes, B., ... \& Castle, H. (2014). How can self-efficacy be increased? Meta-analysis of dietary interventions. Health Psychology Review, 8(3), 270-285. https://doi.org/10.1080/17437199.2013.813729

Prochaska, J. O., \& Velicer, W. F. (1997). The transtheoretical model of health behavior change. American Journal of Health Promotion, 12(1), 38-48. https://doi.org/10.4278/0890-1171-12.1.38

Querstret, D., Morison, L., Dickinson, S., Cropley, M., \& John, M. (2020). Mindfulnessbased stress reduction and mindfulness-based cognitive therapy for psychological health and well-being in nonclinical samples: A systematic review and metaanalysis. International Journal of Stress Management, 27(4), 394 411. https://doi.org/10.1037/str0000165 
Rababah, J. A., Al-Hammouri, M. M., \& Drew, B. L. (2020). The association between mindfulness and health promotion in undergraduate nursing students: A serial multiple mediator analysis. Journal of Advanced Nursing, 76(12), 3464-3472. https://doi.org/10.1111/jan.14556

Rajati, F., Sadeghi, M., Feizi, A., Sharifirad, G., Hasandokht, T., \& Mostafavi, F. (2014). Self-efficacy strategies to improve exercise in patients with heart failure: A systematic review. ARYA Atherosclerosis, 10(6), 319-333. PMID: 25815022

Reed, R. G., Butler, E. A., \& Kenny, D. A. (2013). Dyadic models for the study of health. Social and Personality Psychology Compass, 7(4), 228-245. https://doi.org/10.1111/spc3.12022

Reid, A. E., Cialdini, R. B., \& Aiken, L. S. (2010). Social norms and health behavior. In Handbook of behavioral medicine (pp.263-274). New York: Springer.

Rieder, A., Eseryel, U. Y., Lehrer, C., \& Jung, R. (2021). Why users comply with wearables: The role of contextual self-efficacy in behavioral change. International Journal of Human-Computer Interaction, 37(3), 281-294. https://doi.org/10.1080/10447318.2020.1819669

Roberts, K. C., \& Danoff-Burg, S. (2010). Mindfulness and health behaviors: Is paying attention good for you? Journal of American College Health, 59(3), 165-173. https://doi.org/10.1080/07448481.2010.484452

Roberson, P. N. E., Shorter, R. L., Woods, S., \& Priest, J. (2018). How health behaviors link romantic relationship dysfunction and physical health across 20 years for middle-aged and older adults. Social Science \& Medicine, 201, 18-26.

https://doi.org/10.1016/j.socscimed.2018.01.037 
Robles, T. F., \& Kane, H. S. (2014). The attachment system and physiology in adulthood: Normative processes, individual differences, and implications for health. Journal of Personality, 82(6), 515-527.https://doi.org/10.1111/jopy.12052

Robles, T. F., \& Kiecolt-Glaser, J. K. (2003). The physiology of marriage: Path ways to health. Physiology \& Behavior, 79(3), 409-416. https://doi.org/10.1016/S0031 $\underline{9384(03) 00160-4}$

Robles, T. F., Slatcher, R. B., Trombello, J. M., \& McGinn, M. M. (2014). Marital quality and health: A meta-analytic review. Psychological Bulletin, 140(1), 140-187. https://doi.org/10.1037/a0031859

Rohrbaugh, M. J., Shoham, V., Skoyen, J. A., Jensen, M., \& Mehl, M. R. (2012). We-talk, communal coping, and cessation success in a couple-focused intervention for healthcompromised smokers. Family Process, 51(1), 107-121. https://doi.org/10.1111/j.1545-5300.2012.01388.x

Rothman, A. J., \& Salovey, P. (2007). The reciproc al relation between principles and practice: Social psychology and health behavior. In A. W. Kruglanski \& E. T. Higgins (Eds.), Social psychology: Handbook of basic principles (p. 826-849). New York: Guilford.

Rusbult, C. E. (1983). A longitudinal test of the investment model: The development (and deterioration) of satisfaction and commitment in heterosexual involvements. Journal of Personality and Social Psychology, 45(1), 101-117. https://doi.org/10.1037/0022-

\section{$\underline{3514.45 .1 .101}$}

Rusbult, C. E., \& Arriaga, X. B. (1997). Interdependence theory. In S. Duck (Ed.), Handbook of personal relationships: Theory, research and interventions (pp. 221-250). Hoboken, NJ: Wiley. 
Rusbult, C. E., Johnson, D. J., \& Morrow, G. D. (1986). Determinants and consequences of exit, voice, loyalty, and neglect: Responses to dissatisfaction in adult romantic involvements. Human Relations, 39(1), 45-63. https://doi.org/10.1177/001872678603900103

Rusbult, C. E., Kumashiro, M., Stocker, S. L., \& Wolf, S. T. (2005). The Michelangelo phenomenon in close relationships. In A. Tesser, J. V. Wood, \& D. A. Stapel (Eds.), On building, defending and regulating the self: A psychological perspective (pp. 129). New York: Psychology Press

Rusbult, C. E., \& Van Lange, P. A. M. (1996). Interdependence processes. In E. T. Higgins \& A. W. Kruglanski (Eds.), Social psychology: Handbook of basic principles (pp. 564596). New York, NY: Guilford Press

Schierberl Scherr, A. E., McClure Brenchley, K. J., \& Gorin, A. A. (2013). Examining a ripple effect: Do spouses' behavior changes predict each other's weight loss? Journal of Obesity. https://doi.org/10.1155/2013/297268

Schneider, J., Malinowski, P., Watson, P. M., \& Lattimore, P. (2019). The role of mindfulness in physical activity: A systematic review. Obesity Reviews, 20(3), 448-463. https://doi.org/10.1111/obr.12795

Schulz, U., \& Schwarzer, R. (2004). Long-term effects of spousal support on coping with cancer after surgery. Journal of Social and Clinical Psychology, 23(5), 716-732. https://doi.org/10.1521/jscp.23.5.716.50746

Scholz, U. (2019). It's time to think about time in health psychology. Applied Psychology: Health and Well-Being, 11(2), 173-186. https://doi.org/10.1111/aphw.12156 
Selzler, A. M., Rodgers, W. M., Berry, T. R., \& Stickland, M. K. (2020). Coping versus mastery modeling intervention to enhance self -efficacy for exercise in patients with COPD. Behavioral Medicine, 46(1), 63-74. https://doi.org/10.1080/08964289.2018.1561411

Semenchuk, B. N., Strachan, S. M., \& Fortier, M. (2018). Self-compassion and the selfregulation of exercise: Reactions to recalled exercise setbacks. Journal of Sport and Exercise Psychology, 40(1), 31-39. https://doi.org/10/1123/jsep.2017-0242

Shah, J. (2003). The motivational looking glass: How significant others implicitly affect goal appraisals. Journal of Personality and Social Psychology, 85(3), 424-439. https://doi.org/10.1037/0022-3514.85.3.424

Sheeran, P., Maki, A., Montanaro, E., Avishai-Yitshak, A., Bryan, A., Klein, W. M. P., Miles, E., \& Rothman, A. J. (2016). The impact of changing attitudes, norms, and selfefficacy on health-related intentions and behavior: A meta-analysis. Health Psychology, 35(11), 1178-1188. https://doi.org/10.1037/hea0000387

Shumaker, S. A., \& Hill, D. R. (1991). Gender differences in social support and physical health. Health Psychology, 10(2), 102-111. https://doi.org/10.1037/0278$\underline{6133.10 .2 .102}$

Shor, E., Roelfs, D. J., \& Yogev, T. (2013). The strength of family ties: A meta-analy sis and meta-regression of self-reported social support and mortality. Social Networks, 35(4), 626-638. https://doi.org/10.1016/j.socnet.2013.08.004

Simpson, J. A., Farrell, A. K., Oriña, M. M., \& Rothman, A. J. (2015). Power and social influence in relationships. In M. Mikulincer, P. R. Shaver, J. A. Simpson, \& J. F. Dovidio (Eds.), APA handbook of personality and social psychology, Vol. 3. 
Interpersonal relations (pp. 393-420). Washington, DC: American Psychological Association. https://doi.org/10.1037/14344-015

Simpson, J. A., \& Overall, N. C. (2014). Partner buffering of attachment insecurity. Current Directions in Psychological Science, 23(1), 54-59. https://doi.org/10.1177/0963721413510933

Simpson, J. A., Rholes, W. S., \& Nelligan, J. S. (1992). Support seeking and support giving within couples in an anxiety-provoking situation: The role of attachment styles. Journal of Personality and Social Psychology, 62(3), 434-446. https://doi.org/10.1037/0022-3514.62.3.434

Simpson, J. A., Winterheld, H. A., Rholes, W. S., \& Oriña, M. M. (2007). Working models of attachment and reactions to different forms of caregiving from romantic partners. Journal of Personality and Social Psychology, 93(3), 466-477. https://doi.org/10.1037/0022-3514.93.3.466

Sirois, F. M., Kitner, R., \& Hirsch, J. K. (2015). Self-compassion, affect, and healthpromoting behaviors. Health Psychology, 34(6), 661-669. https://doi.org/10.1037/hea0000158

Skakoon-Sparling, S., \& Cramer, K. M. (2021). Sexual risk taking intentions under the influence of relationship motivation, partner familiarity, and sexual arousal. The Journal of Sex Research, 58(5), 659-670. https://doi.org/10.1080/00224499.2020.1743227

Skoyen, J. A., Blank, E., Corkery, S. A., \& Butler, E. A. (2013). The interplay of partner influence and individual values predicts daily fluctuations in eating and physical 
activity. Journal of Social and Personal Relationships, 30(8), 1000-1019. https://doi.org/10.1177/0265407513479214

Slatcher, R. B., \& Selcuk, E. (2017). A social psychological perspective on the links between close relationships and health. Current Directions in Psychological Science, 26(1), 1621. https://doi.org/10.1177/0963721416667444

Smeets, E., Neff, K., Alberts, H., \& Peters, M. (2014). Meeting suffering with kindness: Effects of a brief self-compassion intervention for female college students. Journal of Clinical Psychology, 70(9), 794-807.https://doi.org/10.1002/jclp.22076

Sobal, J., Rauschenbach, B., \& Frongillo, E. A. (2003). Marital status changes and body weight changes: A US longitudinal analy sis. Social Science \& Medicine, 56(7), 1543 1555. https://doi.org/10.1016/S0277-9536(02)00155-7

Stimpson, J. P., \& Wilson, F. A. (2009). Cholesterol screening by marital status and sex in the United States. Preventing Chronic Disease, 6(2), A55. https://www.cdc.gov/pcd/issues/2009/apr/08_0102.htm

Stimpson, J. P., Wilson, F. A., \& Peek, M. K. (2012). Marital status, the economic benefits of marriage, and days of inactivity due to poor health. International Journal of Population Research, e568785. https://doi.org/10.1155/2012/568785

Stults-Kolehmainen, M. A., \& Sinha, R. (2014). The effects of stress on physical activity and exercise. Sports Medicine,44(1), 81-121. https://doi.org/10.1007/s40279-013-0090-5

Tannenbaum, M. B., Hepler, J., Zimmerman, R. S., Saul, L., Jacobs, S., Wilson, K., \& Albarracín, D. (2015). Appealing to fear: A meta-analysis of fear appeal effectiveness and theories. Psychological Bulletin, 141(6), 1178-1204.

https://doi.org/10.1037/a0039729 
Terry, M. L., \& Leary, M. R. (2011). Self-compassion, self-regulation, and health. Self and Identity, 10(3), 352-362. https://doi.org/10.1080/15298868.2011.558404

Terry, M. L., Leary, M. R., Mehta, S., \& Henderson, K. (2013). Self-compassionate reactions to health threats. Personality and Social Psychology Bulletin, 39(7), 911-926. https://doi.org/10.1177/0146167213488213

Tesser, A., \& Beach, S. R. (1998). Life events, relationship quality, and depression: An investigation of judgment discontinuity in vivo. Journal of Personality and Social Psychology, 74(1), 36-52. https://doi.org/10.1037/0022-3514.74.1.36

Theiss, J. A., Carpenter, A. M., \& Leustek, J. (2016). Partner facilitation and partner interference in individuals' weight loss goals. Qualitative Health Research, 26(10), 1318-1330. https://doi.org/10.1177/1049732315583980

Tucker, J. S. (2002). Health-related social control within older adults' relationships. Journals of Gerontology - Series B Psychological Sciences and Social Sciences, 57(5), 387395. https://doi.org/10.1093/geronb/57.5.P387

Tucker, J. S., \& Anders, S. L. (2001). Social control of health behaviors in marriage. Journal of Applied Social Psychology, 31 (3), 467-485. https://doi.org/10.1111/j.1559$\underline{1816.2001 . t b 02051 . x}$

Tucker, J. S., \& Mueller, J. S. (2000). Spouses' social control of health behaviors: Use and effectiveness of specific strategies. Personality and Social Psychology Bulletin, 26(9), 1120-1130. https://doi.org/10.1177/01461672002611008

Tucker, J. S., Orlando, M., Elliott, M. N., \& Klein, D. J. (2006). Affective and behavioral responses to health-related social control. Health Psychology, 25(6), 715-722. https://doi.org/10.1037/0278-6133.25.6.715 
Turbitt, E., Roberts, M. C., Ferrer, R. A., Taber, J. M., Lewis, K. L., Biesecker, L. G., ... \& Klein, W. M. (2018). Intentions to share exome sequencing results with family members: Exploring spousal beliefs and attitudes. European Journal of Human Genetics, 26(5), 735-739. https://doi.org/10.1038/s41431-018-0118-2

Torres, S. J., \& Nowson, C. A. (2007). Relationship between stress, eating behavior, and obesity. Nutrition, 23(11-12), 887-894. https://doi.org/10.1016/j.nut.2007.08.008

Uchino, B. N. (2006). Social support and health: A review of physiological processes potentially underlying links to disease outcomes. Journal of Behavioral Medicine, 29(4), 377-387. https://doi.org/10.1007/s10865-006-9056-5

Uchino, B. N. (2009). Understanding the links between social support and physical health: A life-span perspective with emphasis on the separability of perceived and received support. Perspectives on Psychological Science, 4(3), 236-255. https://doi.org/10.1111/j.1745-6924.2009.01122.x

Umberson, D. (1987). Family status and health behaviors: Social control as a dimension of social integration. Journal of Health and Social Behavior, 28(3), 306-319. https://doi.org/10.2307/2136848

Umberson, D., Crosnoe, R., \& Reczek, C. (2010). Social relationships and health behavior across the life course. Annual Review of Sociology, 36, 139-157. https://doi.org/10.1146/annurev-soc-070308-120011

Umberson, D., Donnelly, R., \& Pollitt, A. M. (2018). Marriage, social control, and health behavior: A dyadic analysis of same-sex and different-sex couples. Journal of Health and Social Behavior, 59(3), 429-446. https://doi.org/10.1177/0022146518790560 
Umphrey, L., \& Sherblom, J. (2007). Relational commitment and threats to relationship maintenance goals: Influences on condom use. Journal of American College Health, 56(1), 61-68. https://doi.org/10.3200/JACH.56.1.61-68

Valtorta, N. K., Kanaan, M., Gilbody, S., Ronzi, S., \& Hanratty, B. (2016). Loneliness and social isolation as risk factors for coronary heart disease and stroke: Systematic review and meta-analysis of longitudinal observational studies. Heart, 102(13), 1009-1016. https://doi.org/10.1136/heartjnl-2015-308790

Waite, L. J. (1995). Does marriage matter? Demography, 32(4), 483-507. https://doi.org/10.2307/2061670

Walster, E., Berscheid, E., \& Walster, G. W. (1976). New directions in equity research. In L. Berkowitz \& E. Walster (Eds.), Advances in Experimental Social Psychology Vol. 9, (pp. 1-42). New York: Academic Press. https://doi.org/10.1016/S0065-

\section{$\underline{2601(08) 60057-X}$}

Warner, L. M., Stadler, G., Lüscher, J., Knoll, N., Ochsner, S., Hornung, R., \& Scholz, U. (2018). Day-to-day mastery and self-efficacy changes during a smoking quit attempt: Two studies. British Journal of Health Psychology, 23(2), 371-386.

\section{https://doi.org/10.1111/bjhp.12293}

White, E., Hurlich, M., Thompson, R. S., Woods, M. N., Henderson, M. M., Urban, N., \& Kristal, A. (1991). Dietary changes among husbands of participants in a low-fat dietary intervention. American Journal of Preventive Medicine, 7(5), 319-325. https://doi.org/10.1016/S0749-3797(18)30905-X

Williams, L. A., Giddings, L. S., Bellamy, G., \& Gott, M. (2017). 'Because it's the wife who has to look after the man': A descriptive qualitative study of older women and the 
intersection of gender and the provision of family caregiving at the end of life. Palliative Medicine, 31(3), 223-230. https://doi.org/10.1177/0269216316653275

Young, V. J., Burke, T. J., \& Curran, M. A. (2019). Interpersonal effects of health-related social control: Positive and negative influence, partner health transformations, and relationship quality. Journal of Social and Personal Relationships, 36(11-12), 39864004. https://doi.org/10.1177/0265407519846565

Zee, K. S., Bolger, N., \& Higgins, E. T. (2020). Regulatory effectiveness of social support. Journal of Personality and Social Psychology, 119(6), 1316-1358. https://doi.org/10.1037/pspi0000235

Zee, K. S., Cavallo, J. V., Flores, A. J., Bolger, N., \& Higgins, E. T. (2018). Motivation moderates the effects of social support visibility. Journal of Personality and Social Psychology, 114(5), 735-765.https://doi.org/10.1037/pspi0000119

Zhang, Q., Zhao, H., \& Zheng, Y. (2019). Effectiveness of mindfulness-based stress reduction (MBSR) on symptom variables and health-related quality of life in breast cancer patients - a systematic review and meta-analysis. Supportive Care in Cancer, 27(3), 771-781. https://doi.org/10.1007/s00520-018-4570-X 